Star-shaped lactic acid based systems and their thermosetting resins; synthesis, characterization, potential opportunities and drawbacks

7 Contents

8 Abstract

Arash Jahandideh*, Kasiviswanathan Muthukumarappan

Agricultural and Biosystems Engineering Department, South Dakota State University, PO Box

2120, Brookings, SD 57007, USA

*Corresponding author: arash.jahandideh@sdstate.edu

1. Introduction

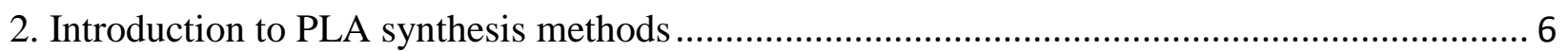

2.1 Synthesis of the PLA by chain extension ............................................................ 7

2.2 Synthesis of star-shaped resins; currently applied monomers as the core molecule............ 9

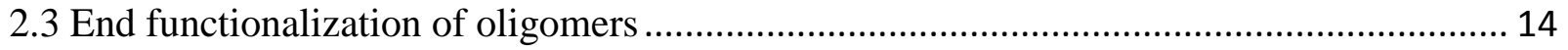

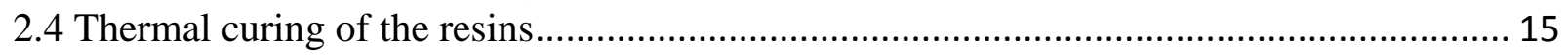

3. Characterization of the S-LA systems ........................................................................ 16

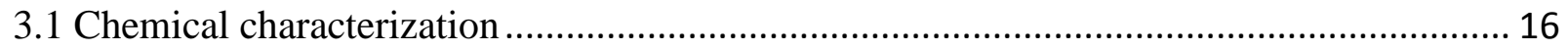

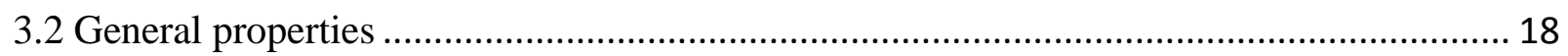

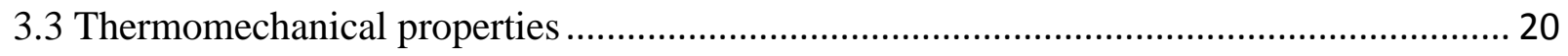

3.4 Rheological properties and curing kinetics of the star-shaped resins ............................ 24

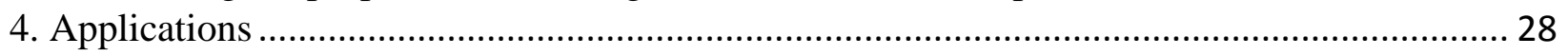

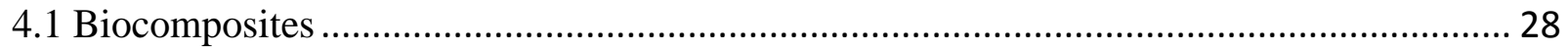

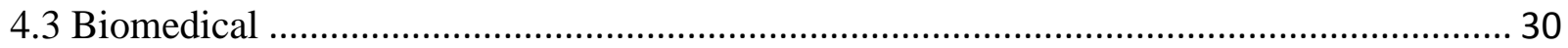

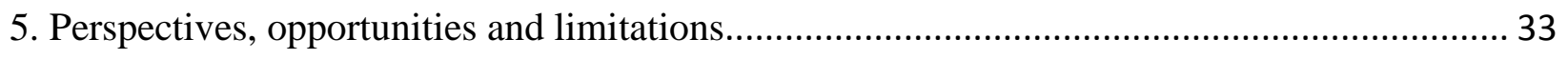

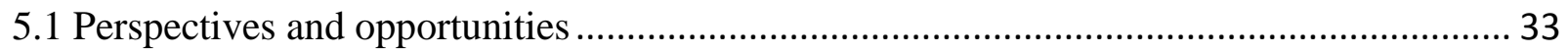

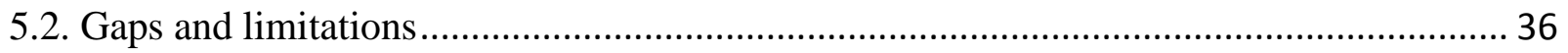

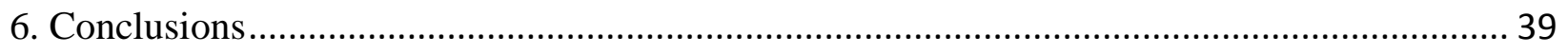

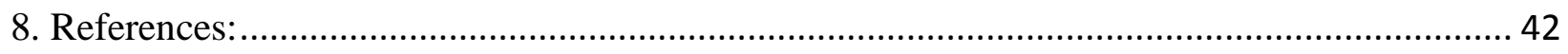

\title{
List of abbreviations:
}

LA: lactic acid

PLA: poly lactic acid

S-LA: star-shaped LA based resins

ROP: ring opening polymerization

EF: end-functionalization

NMR: Nuclear Magnetic Resonance

DMA: dynamic mechanical analysis 
37 TGA: thermogravimetry analysis

38 MW: molecular weight

39 PLGA: poly lactic-co-glycolic acid

40 PGA: poly glycolic acid

41 PEG: poly ethylene glycol

42 PENTA: pentaerythritol

43 IT: itaconic acid

44 MAAH: methacrylic anhydride

45 MAA: methacrylic acid

46 TEG: tetra (ethylene glycol)

47 THMP: 1,1,1-tri(hydroxy methyl)propane

48 DPE: dipentaerythritol

49 TAN: Total Acid Number

50 FT-IR: Fourier transform infrared spectroscopy

51 USDA: U.S. Department of Agriculture

52 E: modulus of elasticity

53 UTS: ultimate tensile strength

54 HRR: heat release rate

55 FDA: Food and Drug Administration

56

\section{$57 \quad$ Abstract}

Shortcomings of the conventional PLA synthesis methods have encouraged researchers to investigate on alternative methods for PLA synthesis. Utilization of chain extenders is an effective way to achieve high MW polymers. The concept of using star-shaped resins as the

61 reinforced matrices for biocomposites or in biomedical applications is gaining more and more

62 attention day by day. Star-shaped lactic acid based resins are a class of branched resins with a

63 multifunctional core molecule and lactic acid branches. In order to increase the reactivity of

64 branches, the star-shaped resin oligomers can get end-functionalized which yields in a

65 crosslinkable product. Changing the architecture of a polymer from a linear to a multiarm or 66 hyperbranched one, would change its chemical, diffusional and physical-mechanical properties.

67 This review paper presents the current state and recent advances in the synthesis, 68 characterization, properties and applications of the star-shaped resins made from lactic acid and multi-hydroxyl core molecules with a focus on the role of the morphology of the polymer on the 
properties of resins. Rheological, physiochemical and thermomechanical properties of to date

71 synthesized star-shaped resins are compared and discussed. Special emphasis would be made on

72 potential opportunities, probable applications and also gaps and drawbacks concerning these

73 systems. This review aims to provide useful information to help future development of efficient,

74 highly engineered bioresins which can be especially designed for a certain application.

75

76 Keywords

77 Star-shaped; Lactic acid; Thermosetting resins; Applications; Limitations

\section{$\underline{\text { 1. Introduction }}$}

Different studies have been published on the synthesis of resins from lactic acid (LA) or

81 lactide and branching point molecules. In order to increase the MW of PLA and induce

82 branching points in the structure, different techniques have been employed, including free-

83 radical branching in the presence of epoxides [1], beam irradiation [2], copolymerization with

84 cyclic monomers having hydroxyl groups in the cycle [3] or use of polyfunctional chain

85 extenders. Generally, the star-shaped resins are synthesized via a two-step strategy: poly-

86 condensation of LA with the core molecule followed by end-functionalization of the branches.

87 So far, star-shaped LA based resins (S-LA) were synthesized employing core molecules such as

88 ethylene glycol, xylitol, glycerol, pentaerythritol for different applications. The rationales for

89 employing a core molecule in the structure of star-shaped polymers are that it increases the MW

90 of the oligomers, lowers the viscosity and enhances processability of the resin; this technique is

91 also provides a better extended network resulting in better thermomechanical properties of the

92 cured resin. In addition, the core molecule will provide reactive sites which can be further used 
93 for the addition of a special functionality, e.g. a flame retardant agent, a drug carrier, an anti94 microbial agent, etc. It is also possible to manipulate the biocomposites' properties by changing 95 the nature and the portion of the block units of copolymers of LA and the core molecule. This 96 manipulation could be in terms of changing the hydrophilicity or designing and altering the 97 voids' sizes of the polymer network. For example, by employing longer oligomers, it is possible 98 to increase the size of the voids in the network and by using hydrophilic monomers, the 99 hydrophilicity of the product can be tailored. Manipulation of both void's size and hydrophilicity 100 will provide the unique opportunity for designing a polymeric matrix for certain component 101 release or a desired drug delivery with a substantial control over release rate. Different methods have been introduced for synthesizing and characterizing the S-LA. 103 The differences between the S-LA properties, resulted from employing of different core 104 molecules, different lengths of the LA (or co-polymers) monomers in branches, utilization of 105 different end-functionalization (EF) agents, employing different curing techniques as well as 106 using different curing initiators. Choosing a combination of these sets results in a unique product 107 with specific characteristics which could be suitable for a certain purpose. The concept of using 108 star-shaped resins as the reinforced matrices for biocomposites or in biomedical applications is 109 gaining more and more attention day by day. The increasing number of publications during the 110 recent years, concerning the synthesis and characterization of star-shaped resins for different 111 applications, including biocomposites [4-7], coating [8], biomedical [9, 10], drug delivery [11112 13], tissue engineering [14], smart packaging, functionalized polymers [15, 16] and so on, 113 reflects the growing importance of these new resins. To date, there is no comprehensive study 114 exists on the different synthesis methods and characteristics of the synthesized S-LA. 
This review paper presents the recent advances in the synthesis, characterization, properties and applications of S-LA and their thermosetting systems using a multi-hydroxyl

117 clustering core molecule. The synthesis, chemical and thermomechanical properties of S-LAs are 118 assessed. Special emphasis would be made on potential opportunities, probable applications and 119 also drawbacks concerning the use of the multi-hydroxyl core molecules in the structure of the S120 LA. Finally, the limitations and technological gaps of these systems are highlighted. This paper 121 will not address other branched LA based polymers, including dendrimers, hyperbranched, 122 grafted or comb-like polymers; and also, synthetic fiber reinforcements for bio composites are 123 out of the scope of this paper. In addition, studies on fiber treatment for composite productions 124 are excluded from this review article.

125 This review paper consisted of four different sections. In the first part, the synthesis of 126 the S-LAs are explored. Different synthesis methods of PLA are discussed and currently applied 127 multi-hydroxyl monomers as the core molecule for S-LAs are introduced. The role of EF and 128 attributed methods of end-functionalizing of the branches as well as different methods for curing 129 of the resins are emphasized. In the second part, the characterization of the S-LAs are discussed, 130 including chemical characterization, general properties and thermomechanical properties. In 131 chemical characterization, titration, nuclear magnetic resonance (NMR) and Fourier transform 132 infrared spectroscopy (FT-IR) of S-LAs are discussed briefly. Special emphasis are made on 133 rheological properties and curing kinetics of the star-shaped resins. The general properties 134 section presents the current knowledge on water absorption properties, the biobased contents and 135 the morphological properties of the S-LAs. Finally, the thermomechanical properties of the cured 136 resins are discussed based on the reported results of dynamic mechanical analysis (DMA), 137 flexural, tensile and charpy testing as well as the thermogravimetry analysis (TGA). The third 
138 part will discuss different applications of these systems, including biocomposites, drug delivery,

139 biomedical and tissue engineering. In the fourth part, the limitations and future of these systems

140 are discussed.

\section{Introduction to PLA synthesis methods}

Lactic acid (2-hydroxy propionic acid) exists as the two stereo isomers of L-LA and D-

143 LA, and can be produced via bacterial fermentation of carbohydrates or chemical synthesis. The

144 LA produced by the chemical rout is an optically inactive racemic mixture (50/50 L-D) while

145 fermentation-derived LA exists almost exclusively as L-LA [17]. Due to major limitations of

146 chemical synthesis, the fermentation pathway is often preferred $[18,19]$. Poly lactic acid (PLA),

147 an aliphatic polyester made up of LA monomers, is a biodegradable and compostable

148 thermoplastic which has extensive applications in biomedical fields, including bone fixation, 149 drug delivery and tissue engineering. The applications of PLA are not limited to biomedical field 150 and it has potential for use in a wide range of applications, including food applications, 151 packaging, structural composites, furnishings, etc. [19, 20].

Synthesis of PLA from LA can follow two different routes of polymerization, including

153 condensation polymerization of LA and polymerization through lactide formation [19]. The

154 condensation polymerization route includes direct condensation-polymerization of LA and 155 azeotropic dehydration condensation of LA. In direct condensation-polymerization, esterification 156 of monomers happens with the aid of solvents and the consequent water is removed 157 progressively at high temperatures and partial vacuum. The molecular weight of the 158 condensation derived polymer would be low, which results in poor mechanical properties [19, 159 21]. In azeotropic dehydration-condensation method, the azeotropic solution and catalysts are 
160

161

162

163

164

165

166

167

168

169

170

171

172

173

174

175

176

177

178

179

180

181

182

employed to produce a high molecular weight PLA. The azeotropic solution helps to reduce the distillation pressure and enables the separation of the PLA from the solvent. In general, polycondensation methods require a good control over the reaction for achieving a PLA with desired MW, and water, as a byproduct of the condensation, must be efficiently removed from the solution for achieving a high MW PLA [22]. In the lactide formation pathway or ring opening polymerization (ROP), first LA is dimerized to lactide. Adding a proper catalyst at elevated temperatures under vacuum, the PLA is synthesized with relatively high MW. Reaction time, temperature, purity of lactide and type of the employed catalysts are of the key parameters in ROP method [23]. The ROP of LA is a complicated and expensive method for production of high MW PLA and condensation methods result in low MW PLA [24].

\subsection{Synthesis of the PLA by chain extension}

In direct polymerization (also called solution poly-condensation or melt polycondensation), LA is condensate polymerized to yield a low MW brittle glassy polymer. Presence of water, the high viscosity of the polymer melt, the presence of impurities, low concentration of reactive groups and occurrence of the unwanted "back biting" reactions which result in lactide formation are of reasons for achieving a low MW polymer [21, 25]. Therefore, this polymer is not suitable for any application without further utilization of the external coupling agents which are employed to increase the MW of the polymer [21]. Azeotropic condensationpolymerization is also sensitive to the presence of impurities of the supplied LA. The impurities endcap the polymer and limit the chain growth and have a large effect on the MW of the final polymer. In addition, in azeotropic condensation-polymerization, various diacids, diols or hydroxyl acids interfere with polymerization step and affect the purity of the produced polymer. Residual catalysts in the products would be another drawback of this method [21]. 
From the other hand, the yield and efficiency of ROP method heavily depend on the type 184 of the employed catalyst and the employed polymerization mechanism. Cationic [26], anionic 185 [27] and coordination-insertion [21] are the three mechanisms of catalytic reactions in ROP, 186 which are sensitive, complex and expensive [28]. Tin compound catalysts, e.g. tin (II) bis-2187 ethylhexanoic acid (referred to as tin octoate or stannous octoate) are the most common catalysts 188 used in the ROP method [29]. It is shown that the rate of chain growth varies greatly depending 189 on the presence of lactide impurities and also by formation of crystalline phase during 190 polymerization. It is believed that the presence of impurities does not significantly affect the rate 191 of polymerization, but it dramatically reduces the final MW of the polymer. However, carboxylic 192 impurities have an inhibitory effect on the rate of polymerization as well, which could be due to 193 deactivation of the catalyst by forming a complex. Substantial sensitivity of the ROP method to 194 impurities, indicates that a rigorous purification of lactide is required beforehand in those 195 processes which impose substantial costs to the process $[21,30]$.

Shortcomings of the direct condensation methods and complexity of ROP, encouraged 197 researchers to investigate on alternative methods for PLA synthesis. Utilization of chain 198 extenders is an effective way to achieve high MW polymers. Generally, chain extenders are 199 multifunctional low MW chemicals which are attached to the low MW oligomer and link it into a 200 polymer with higher MW. The most common chain extenders for polyesters which contain $-\mathrm{OH}$ 201 and - $\mathrm{COOH}$ groups include diisocycanates, diepoxides, bisoxazolines, dianhydrides and 202 bisketeneacetals [21, 30]. 

217 are explored.

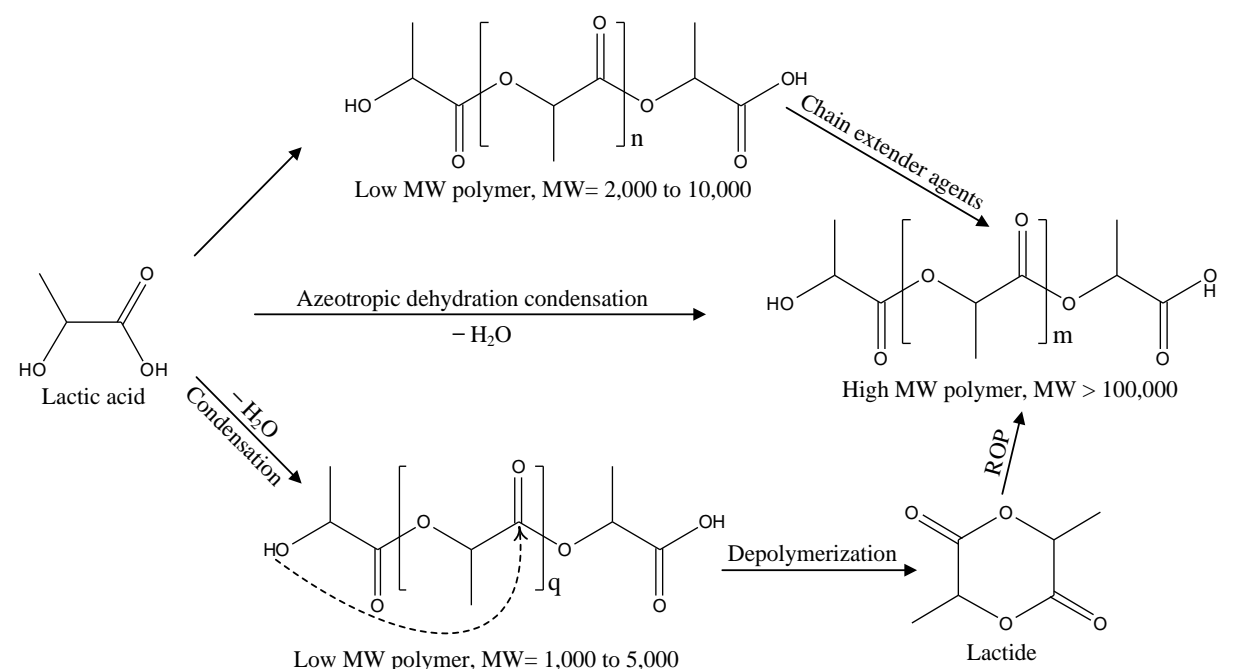

Figure 1, PLA synthesis methods.

\section{$\underline{\text { 2.2 Synthesis of star-shaped resins; currently applied monomers as the core molecule }}$}

Currently, polymers are designed for a certain application. In order to add especial physical properties, it is sometimes desirable to change the architecture of the polymer from linear to a star-shaped polymer [15]. Changing the architecture of a polymer to achieve a multiarm or hyperbranched one would change its morphological and physical-mechanical properties [31]. Different methods for achieving star-shaped polymers have been introduced, including employ of multifunctional linking agents or multifunctional initiators [15, 32-36]. However, a few studies have been devoted to syntheses of star-shaped polyesters. The early starshaped polyesters have been synthesized by the reaction of multifunctional hydroxyl compounds and octoate using an ROP approach [37, 38]. Currently, different polyol molecules with various hydroxyl groups have been employed as the core molecule in S-LA. In the next part of this review article, the recent methods for synthesis of different star-shaped resins using these polyols

Core molecules with two hydroxyl groups: Poly lactic-co-glycolic acid (PLGA) is a copolymer of PLA and poly glycolic acid (PGA), (see fig 2-5) which has been used to fabricate 
220 devices for drug delivery and tissue engineering applications for decades [39, 40]. Physical 221 properties of PLGA are dependent on multiple factors, including the MW of the polymer, the 222 ratio of lactide to glycolide (see fig 2-4) in the structure, time of exposure to water and the 223 surface shape [41]. Polymers can be synthesized using ethylene glycol (see fig 2-3) and lactic 224 acid as either random or block copolymers. PLGA/PEG block copolymers have been synthesized 225 as diblock oligomers of PLGA-PEG [42] or triblock oligomers of PLGA-PEG-PLGA [43] and 226 PEG-PLGA-PEG [44]. Generally, PLGA copolymers are synthesized by ring-opening 227 copolymerization of d,1-lactide and glycolide and common catalysts used include tin(II)2228 ethylhexanoate, tin(II)alkoxides, or aluminum isopropoxide. The copolymerization happens by 229 ester linkage of successive monomeric units of glycolic or lactic acid, which yields a linear, 230 aliphatic polyester [45, 46]. Tetra(ethylene glycol), TEG, has also been used as the chain 231 extender and telechelic polylactides having two $\mathrm{CH}-\mathrm{OH}$ end groups were obtained. The ratio of 232 LA to TEG was set to 20:1 mole and dry chlorobenzene was added under an atmosphere of dry 233 nitrogen. The reactants were heated to $120^{\circ} \mathrm{C}$ and after $5 \mathrm{~min}, \mathrm{Bi}(\mathrm{OAc})_{3}$ was added - with a ratio 234 of 0.02 mole to mole of TEG [47]. Biela et al. employed diethylene glycol (see fig 2-2) as 235 another chain extender with two hydroxyl groups and synthesized hydroxyl group terminated R$236(\mathrm{PLA}-\mathrm{OH})_{2}$ according to the procedure employing $\mathrm{Sn}(\mathrm{Oct})_{2}$ as co-initiator. Sealed glass ampules 237 using a standard high vacuum technique were employed for polymerization at $120^{\circ} \mathrm{C}$ [48]. 238 Butanediol (see fig 2-1) is also used as the chain extender in synthesis of the S-LA. The 239 oligomers were polymerized via ROP method from d,1-lactide at $160^{\circ} \mathrm{C}$ for $3 \mathrm{~h}$. In the presence 240 of 0.02 mole \% $\mathrm{Sn}$ (II)octoate as an initiator, the appropriate amount of the extender to LA 241 molecules were added in which the ratio of the LA monomer to butanediol was varied between $242 \quad 100: 12.5$ to $100: 5[49]$. 
244 glycerol (see fig 2-6) core molecules. The resin was synthesized in two stages: direct 245 condensation reaction of LA with glycerol and EF of the oligomers with MAAH. Resins with 246 different LA chain lengths of 3, 7 and 10 were synthesized using 9, 21 and 30 moles of LA per 247 glycerol mole. Condensation reactions performed in the presence of toluene reflux from an 248 azeotropic distillation apparatus (50 $\mathrm{g}$ toluene per LA mole) as an auxiliary solvent for water 249 removal containing $0.1 \mathrm{wt} \%$ of the catalyst, methanesulfonic acid. The temperature was set to $250145^{\circ} \mathrm{C}$ for two hours, increased to $165^{\circ} \mathrm{C}$ for another two hours and to $195^{\circ} \mathrm{C}$ for one more hour. 251 For EF, in the presence of $0.1 \mathrm{wt} \%$ of hydroquinone as the stabilizer, 3.3 mole MAAH per mole 252 of glycerol was added under a nitrogen atmosphere. The resin was purified from the remained 253 water/toluene and the produced MAA by a rotary evaporator at 13 mbar at $60^{\circ} \mathrm{C}$ for 2 hours [4]. 254 In a more recent study, tri(hydroxymethyl)benzene (see fig 2-7), has been used as the core 255 molecule using a tin octanoate catalyst, for producing S-LA oligomers with 10 lactide monomer 256 units arms. Polymerization reaction was performed at $125^{\circ} \mathrm{C}$ for $8 \mathrm{~h}$ under nitrogen atmosphere. 257 The precipitation in cold methanol was employed for separation of the polymers from the 258 reactants [50]. 1,1,1-tri(hydroxymethyl)propane (THMP) (see fig 2-8) has also been used as the 259 core molecule where a three-armed S-LA with three $\mathrm{CH}-\mathrm{OH}$ end groups was formed. The ratio 260 of lactide to THMP was 20:1 mole to mole and dry chlorobenzene was added under an 261 atmosphere of dry nitrogen. The reactants were heated to $150^{\circ} \mathrm{C}$ for homogenization before 262 cooling to $120^{\circ} \mathrm{C}$ and after $5 \mathrm{~min}, \mathrm{Bi}(\mathrm{OAc})_{3}$ was added with a ratio of 0.02 mole to mole of 263 THMP [47, 48]. In another similar study, the same core molecule, THMP, was used with tin(II) 264 octoate $\left[\mathrm{Sn}(\mathrm{Oct})_{2}\right]$ as initiator in which lactide was polymerized with $\mathrm{Sn}(\mathrm{Oct})_{2}$ with the polyol, at $265120^{\circ} \mathrm{C}[16]$. 

preparation of higher MW S-LA with pentaerythritol (PENTA) (see fig 2-9) as the core molecule. The initiator was octoate and the resulted resin showed a lower intrinsic viscosity 269 compared to those of the linear ones, which confirms the lower viscosity of the star-shaped 270 architecture [37, 51]. Åkesson et al. synthesized a crosslinkable thermoset resin from LA and 271 PENTA core molecules. The resin was synthesized via direct condensation reaction of LA with 272 PENTA and itaconic acid (IT) followed by $\mathrm{EF}$ of the oligomers with MAAH. At $120^{\circ} \mathrm{C}$, the 273 catalyst, $0.05 \mathrm{wt} \%$ of tin octoate, was added, and the reaction temperature was set to $180^{\circ} \mathrm{C}$. The total polymerization time was $15 \mathrm{~h}$ and the resulted product was a yellowish, transparent, rigid, 275 brittle resin. It is assumed that IT was only reacted with one branch of PENTA. For EF at 100$276110^{\circ} \mathrm{C}$, first, $0.1 \mathrm{wt} \%$ of hydroquinone was added as the stabilizer and then, $15 \mathrm{wt} \%$ of MAAH 277 was added dropwise. The reaction continued at $120^{\circ} \mathrm{C}$ for $3 \mathrm{~h}$ under nitrogen purge [8]. In 278 another study, Biela et al. synthesized four hydroxyl groups terminated R-(PLA-OH) $)_{4}$ employing 279 di(trimethylolpropane) (see fig 2-10) as the core molecule according to the procedure employing $280 \mathrm{Sn}(\mathrm{Oct})_{2}$ as the co-initiator- which is previously explained [48].

282 fig 2-11) molecule was examined and evaluated as the core molecule in an S-LA resin. The resin was synthesized via direct condensation reaction of LA with xylitol, in the presence of toluene reflux from an azeotropic distillation apparatus. $50 \mathrm{~g}$ toluene per mole of LA was initially added 285 as an auxiliary solvent for water removal containing $0.1 \mathrm{wt} \%$ of the catalyst, methanesulfonic acid. The reaction temperature was set to $145^{\circ} \mathrm{C}$ for two hours and then increased to $165^{\circ} \mathrm{C}$ for 7 287 hours. The branches were then end-functionalized at $90^{\circ} \mathrm{C}$ with methacrylic anhydride $(5.5$ mole MA per mole of LA) in the presence of $1 \mathrm{wt} \%$ hydroquinone. Finally, under partial vacuum, the 
residual toluene and the released methacrylic acid were removed - 10 mbar, $1 \mathrm{~h}$ at $60{ }^{\circ} \mathrm{C}$ and two hours at $90{ }^{\circ} \mathrm{C}[52]$.

Core molecules with more hydroxyl groups: Biela et al. reported the synthesis of S-LA with higher hydroxyl groups -6 and 13- arms. The dipentaerythritol (DPE) (see fig 2-13) core molecules were used to produce 6 arms S-LA with $\mathrm{Sn}(\mathrm{Oct})_{2}$ coinitiator with the same technique at $120^{\circ} \mathrm{C}$. The same technique was employed for synthesizing 13 arms S-LA with poly(3-ethyl3-hydroxymethyloxetane) (see fig 2-14) as the core molecule [53]. Perry and Shaver also synthesized and characterized a S-LA, using cyclic hexa(hydroxymethyl)benzene core molecule (see fig 2-12) and a tin octanoate catalyst with 10 lactide monomer units in arms. Polymerization reaction was performed at $125^{\circ} \mathrm{C}$ for $8 \mathrm{~h}$ under nitrogen atmosphere [50].
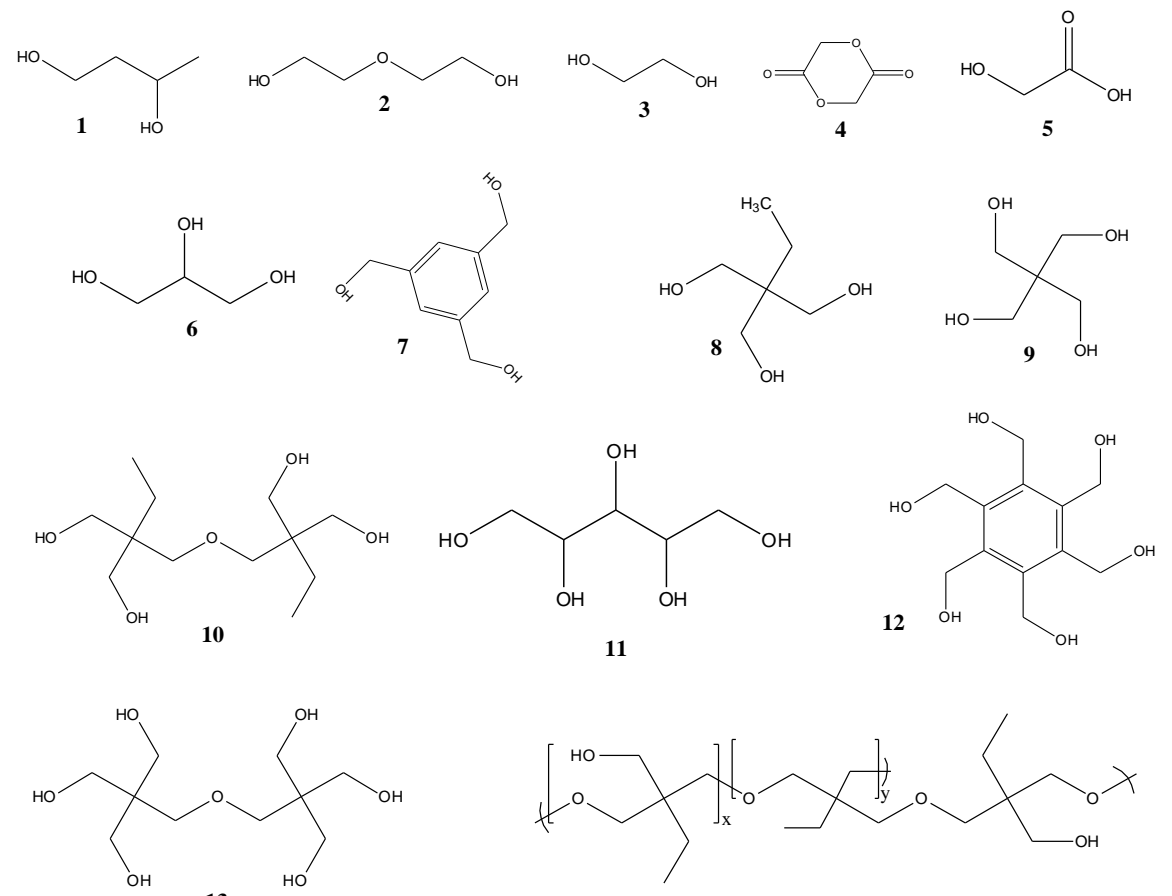

$14\langle\mathrm{x}+\mathrm{y}\rangle=13.4$

Figure 2. Currently applied monomers as the core molecule in S-LA resins. 1:Butanediol, 2:diethylene glycol, 3:ethylene glycol, 4:glycolide, 5:glycolic acid, 6:glycerol, 7:tri(hydroxymethyl)benzene, 8:1,1,1-tri(hydroxymethyl)propane, 9:pentaerythritol, 10:di(trimethylolpropane), 11:xylitol, 12:hexa(hydroxymethyl)benzene, 13:dipentaerythritol, 14:poly(3-ethyl-3-hydroxymethyloxetane). 
The star-shaped oligomers resulted from the condensation reaction of LA with a multifunctional 307 hydroxyl core molecule, would have reactive groups (either the terminal LA's hydroxyl groups or the 308 core molecules' unreacted hydroxyls) but yet, the groups are not reactive enough for a satisfactory cross309 linking $[8,52]$. In order to produce a thermoset, capable of efficient crosslinking, branches must be 310 further functionalized- or end capped- with an EF agent. The role of EF is to improve the reactivity of 311 branches, generally by adding carbon-carbon double bonds. The stoichiometric amount of the EF agent 312 will be calculated from the theoretical molecular weight of the synthesized oligomer and the functionality 313 of the co-initiator [49]. Common EF agents presented in the literature are MAA [7] (see fig 3-2), MAAH $314[4,52,54-56]$ (see fig 3-1) or IT [7] (see fig 3-3). The two olefinic bonds of the MAAH, bestow a higher 315 reactivity to the molecule and make it more desired for EF purpose, compared to other EF agents. 316 Usually, a stabilizer agent, e.g. hydroquinone, is used to protect the olefinic carbon-bonds during the EF 317 reactions and avoid subsequent cross-linking reactions and gelation. Generally, EF reactions are sensitive 318 to high temperatures, which induce gelation inside the reactor; therefor, a good control over the 319 temperature is required. 

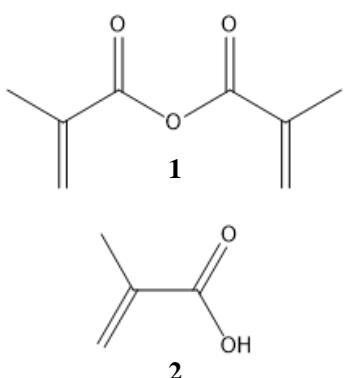

2

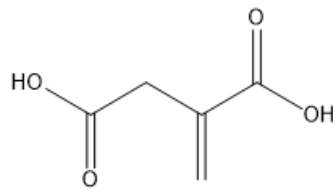

3

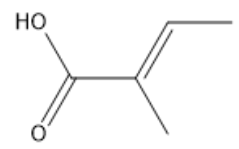

4

Figure 3, End functionalization agents. 1: methacrylic anhydride (MAAH), 2: methacrylic acid (MAA), 3: itaconic acid (IT), 4: crotonic acid.

\section{$\underline{\text { 2.4 Thermal curing of the resins }}$}

Curing involves the irreversible transformation of low molecular weight oligomers of a resin into a solid network [57]. The liquid resin is usually composed of several ingredients with three or more reactive groups per molecule that can react by an external action, such as heating or UV irradiation which results in a tridimensional cross-linked structure [58]. Generally, thermal curing of resins consists of two different stages: the heating period and curing reaction phase. During the heating period, the heat is transferred by conduction through the resin which is heated up to a temperature at which the cure reactions start. In the curing reaction phase, the heat evolved from the overall cure reaction zone at a constant temperature which can be described by an Arrhenius equation [57]. Often, in the S-LAs, a free-radical polymerization method is employed for curing in which the reaction starts by the assistance of a radical initiator. The common studied initiators for free radical polymerization are benzoyl peroxide $[4,19,59], 2,5-$ bis(tert-butylperoxy)-2,5-dimethylhexane [14], 2-butanone peroxide [49], cobalt naphthenate 
[15], tert-butyl peroxybenzoate [8], N,N-dimethylaniline [5] and tert-butyl peroxybenzoate [7,

56]. Different factors are involved in free radical curing reactions, including the nature of the initiator, initiator-to-resin ratio, applied heat regimes, retention times and cooling strategies. Often, 1-2 wt\% of the initiator is utilized for the thermal curing. Using excess amount of the curing agent or applying high temperatures for curing may result in higher exotherms, faster gelation and more shrinkage due to excessive thermal zoning [52,60]. Figure 4 presents the reaction Scheme for the synthesis steps and the curing reaction.
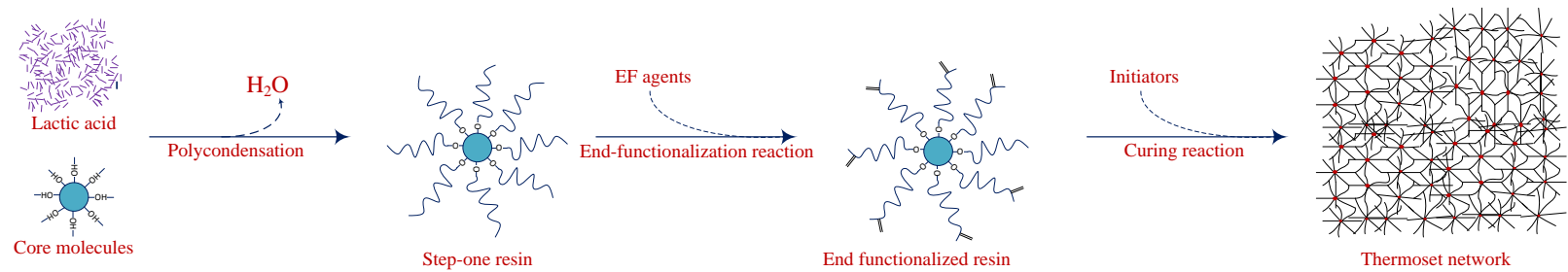

Thermoset network

\section{Figure 4. Reaction Scheme for the two-step synthesis of the S-LA and the thermosetting} network

\section{Characterization of the S-LA systems}

\section{$\underline{\text { 3.1 Chemical characterization }}$}

Titration: The condensation retention time is a crucial factor in poly-condensation step.

From one hand, insufficient retention time in the reactor results in unreacted reactants and from the other hand, excessive reaction time results in transesterification reactions, which gradually degrades the structure of the oligomers [52]. The progress of the condensation reaction can be evaluated by determination of the Total Acid Number (TAN) for residual acidic constituents (carboxyl groups) during the poly-condensation step. According to the ASTM D974-12, the TAN is defined as the quantity of $\mathrm{KOH}$ (in $\mathrm{mg}$ ), required for the titration of $1 \mathrm{~g}$ of the sample which is dissolved in a specified solvent system. The samples are diluted in predefined solvent systems, capable of dissolving the S-LA, and then, titrated with a base in the presence of an 
357 indicator, e.g. phenolphthalein 1\% [61]. The currently used solvent systems for the TAN 358 determination are 1:1 v/v xylene/isopropyl alcohol solutions [4, 52, 61], acetone [62] and a 359 mixture of toluene and isopropyl alcohol (based on the ASTM D664 and D974-12). The ratio of 360 the reacted to initial available carboxylic groups, indicates the degree of completion of the 361 condensation reaction.

NMR: The Nuclear magnetic resonance (NMR) is a technique frequently used for 363 identifying the chemical structure of the synthesized resins as well as LA chain length in the 364 branches. The ${ }^{13} \mathrm{C}$ NMR data for different S-LA is presented in the literature $[4,8,11,12,38,49$, $36552,61,63,64]$. Of particular interest is the carbonyl region (160-180 ppm) [5, 52]. For neat S366 LA, different types of carbonyl bonds are expected, including a) main-chain carbonyls, b) LA 367 carbonyl groups adjacent to the $\left(-\mathrm{O}-\mathrm{CH}_{2}\right)$ branches of the core molecule, and c) carbonyls of the 368 LA end-group for unreacted LA. For the end-functionalized resins, signals in the carbonyl area 369 would be broad, because signals for carbonyls of LA next to the core molecule (or next to the 370 end-capping agent) differ from that of LA in chains. In addition, the end-group agent may add 371 other carbonyl bands. The other class of chemical shifts used for characterization, belongs to a 372 carbon atom adjacent to an oxygen atom which is revealed in the range of 60-75 ppm [65]. 373 These $\mathrm{CH}$ groups could be a) in the structure of the core molecule, b) next to the reacted LA 374 carbonyl groups and an oxygen atom, or c) adjacent to the hydroxyl end-group. The other 375 expected groups are methyl groups. The LA methyl groups are detected in the 16-22 ppm range 376 [52]. Hydroxyl functionalized end-group of methyl groups are present in the S-LA, but not 377 present in the EF resins. The probable $\mathrm{CH}_{3}$ groups of the end-capped agent in the resin structure 378 and the olefinic carbon sites of the end-groups are other characteristic signals of the EF resins. 379 Moreover, the NMR technique can also be used for measuring the chain length of the branches 
380 [5], the percentage of the LA in forms of reacted with the core molecule as well as the 381 percentage of the LA reacted into free oligomers [4, 52].

FT-IR: The FT-IR analysis of the S-LA is often performed for verifying the structure of poly-condensation resins, the EF resins and also the cured samples. Infrared spectroscopy data of the S-LAs' functional groups is presented in the literature $[4,5,8,13,56,63,65-68]$ and summarized in the following Table (table 1). Different groups might appear in the IR spectra of the S-LA, EF resins and the cured samples. Generally $(-\mathrm{OH})$ Stretch spectra is just present in poly-condensation resins as hydroxyl groups will react with an EF agent during the end-capping reactions. The spectra for $(-\mathrm{CH}-$ stretch and bend $),(-\mathrm{C}=\mathrm{O}$ carbonyl stretch $)$ and $(-\mathrm{C}-\mathrm{O}-\mathrm{C}-$ Stretch), generally presented in all samples. The spectra for $(-\mathrm{C}=\mathrm{C}-$ stretch $)$ and $\left(=\mathrm{CH}_{2}\right.$ bending) are just expected in EF resins in which carbon-carbon double bonds are present.

Table 1. Infrared spectroscopy data of the S-LAs' functional groups.

\begin{tabular}{ll}
\hline Assignment & Peak position, $\mathrm{cm}^{-1}$ \\
\hline$-\mathrm{OH}$ Stretch (free) & $3380[67], 3428[5], 3491[63], 3500[4,5], 3506[13], 3508[56], 3520[66,67]$ \\
\hline$-\mathrm{CH}-$ stretch & $2870[13], 2879[66], 2900[4], 2994-2943[63], 2947[13], 2990[65]$ \\
\hline$-\mathrm{CH}-$ bend & $1382-1454[63], 2947[13]$ \\
\hline$-\mathrm{C}=\mathrm{O}$ carbonyl stretch & $1705[67], 1722$ (MAAH) [56], 1734 [13], 1749 [56], 1755 [63], 1757 [5], 1758-1763 [66], 1759 [5] \\
\hline$-\mathrm{C}=\mathrm{C}-$ stretch & $1635[4], 1638[56], 1640[4,5,8]$ \\
\hline$=\mathrm{CH}_{2}$ bending & $815[68], 816[4,5,56,68]$ \\
\hline$-\mathrm{CH}_{3}$ & $1453,2999[13]$ \\
\hline$-\mathrm{C}=\mathrm{O}$ bend & $757[66]$ \\
\hline$-\mathrm{C}-\mathrm{O}-\mathrm{C}-$ Stretch & $1095-1130[66], 1170[13], 1271-1188-1093[63]$ \\
\hline$-\mathrm{CH}$ ring of lactide & $932-934[66]$
\end{tabular}

3.2 General properties

Water absorption: The water absorption rates of polymers and composites are of interest, especially when the material is supposed to exposure to relatively humid conditions. The moisture content affects polymers' properties such as electrical insulation resistance, dielectric losses, mechanical strength, appearance, and dimensions. It is believed that the diffusion of water 
into polymer matrix is dependent to several factors, including a) the square root of immersion

399 time, b) the type of immersion, c) dimensions and shape of the specimen and d) the inherent 400 properties of the polymer [52,69]. In composites, the type and characteristics of the reinforced 401 fiber also affect the water uptake. For example, using the same matrix, the flax/basalt composites 402 showed a lower water uptake than the flax composites [6, 70]. The fiber volume fraction of the 403 composite is also believed to be proportional to the water uptake rate of the composite [61, 71]. 404 The water absorption tests are generally carried out based on the ASTM D 570-98 in 3 modes: 405 Long-Term Immersion, Two-Hour Boiling Water Immersion and Immersion at 50 ${ }^{\circ}$. In Long406 Term Immersion, the sample is immersed in a distilled water bath at $23^{\circ} \mathrm{C}$ and the total water 407 absorption versus time is recorded, in the two-hour-boiling-test, the water absorption is measured 408 after 2 hours of immersion in the boiling distilled water bath and in the Immersion at $50^{\circ} \mathrm{C}$ mode, 409 water absorption is measured at $50^{\circ} \mathrm{C}$ at different time intervals. Tests are continued until the 410 samples get substantially saturated (achieved water absorption rates to be $\leq 1 \%$ or $5 \mathrm{mg}$ between 411 intervals). The initial slope of the water-absorption versus time curve is proportional to the 412 diffusion constant of water in the matrix [69]. Biobased content: The biobased content or "Percent biobased" is a measure of the 414 proportion of the biobased carbon fraction to the total carbon in the product. The ASTM D6866 415 has set a standard method based on radiocarbon analysis for the calculation of the biobased 416 content included in a resin, which is frequently used for measuring the biobased content of resins $417[52,54,72]$. This standard method is also used by the U.S. Department of Agriculture (USDA) 418 BioPreferred program ${ }^{1}$ to calculate the biobased content included in a material. Based on this 419 standard, the biobased standard can be calculated using the following formula:

\footnotetext{
${ }^{1}$ https://www.biopreferred.gov/BioPreferred/
} 


$$
\text { Biobased content }=\frac{\text { biobased carbon content }}{\text { total carbon content }} \times 100
$$

420 The total carbon content includes both renewable based and petroleum based carbons.

\section{$421 \quad 3.3$ Thermomechanical properties}

In this part, the effect of external forces on the behavior of cured S-LA thermosets and

423 their composites are discussed and the thermomechanical tests currently employed in

424 determining various properties, including elastic modulus, yield stress, ultimate strength,

425 toughness, flexural modulus, storage modulus, flexural modulus and glass transition temperature

426 are highlighted. The mechanical tests currently employed in characterizing thermomechanical

427 properties of S-LA thermosets, including DTMA tests, tension tests, compression tests, bending

428 or flexural tests, hardness tests, fatigue tests, creep tests, thermogravimetry analysis, dynamic

429 scanning calorimetry and impact tests. The type of the employed testing methods on the

430 specimen depends on the service expected for the produced thermoset. However, the more

431 testing applied on a specimen, the more information acquired for the intended S-LA. The

432 mechanical properties of S-LA is very dependent on the molecular weight and the structure of

433 the network. Generally, employ of a star branching point in the S-LA systems, results in lower

434 melting temperatures $\left(\mathrm{T}_{\mathrm{m}}\right)$, lower glass transition temperatures $\left(\mathrm{T}_{\mathrm{g}}\right)$ and lower crystallization

435 temperatures $\left(\mathrm{T}_{\mathrm{c}}\right)$ for polycondensation resins. The lower $\mathrm{T}_{\mathrm{c}}$ indicates that the staring points

436 make the material harder to crystallize, while lower $T_{m}$ indicates that it makes stacking of the

437 polymers more difficult [73]. The following section provides a short description of the current

438 mechanical testing methods and the type of information obtained from these methods.

440 mechanical properties of S-LA based matrices. In tensile tests, a specimen is subjected to a 441 controlled tension until failure happens and stress to strain curve is obtained. The modulus of 
442 elasticity (Young's modulus), E, is a measure of the stiffness of the sample in the linear region of

443 the curve in which the specimen can return to its exact initial conditions, if the load is removed;

444 the yield strength is the stress applied to the material at which plastic deformation starts to occur;

445 and ultimate tensile strength (UTS) is the maximum load the specimen sustains during the test.

446 Increasing the temperature generally increases the ductility (the extent of plastic deformation

447 before fracture) and the toughness of a material while decreases the yield stress, tensile strength

448 and the modulus of elasticity $[74,75]$. It is believed that the tensile properties of the star-shaped

449 structure are different with linear oligomers. The strength can be lower for networks with

450 flexible extension units, or higher for structures with rigid staring points. It is reported that S-LA

451 systems with high crosslinking density demonstrate similar mechanical properties to those of

452 other biodegradable composites, however, longer LA chains will decrease tensile properties [49].

453 Helminen et al. reported lower tensile strength for butanediol-LA systems (despite higher

454 crosslinking density), which was ascribed to the flexible butanediol units used in the linear

455 oligomers [49]. However, it is believed that the tensile strength is a function of crosslinking

456 density and generally, a higher crosslinking density results in higher tensile strength [76]. In

457 compression tests, the specimen is subjected to a compressive load usually by a solid cylindrical

458 object between two well-lubricated flat platens. For the brittle materials, a disk test is applied

459 instead, in which the disk is subjected compression and uniform tensile stresses develop

460 perpendicular to the centerline of the disc $[75,77]$. The bending, flexural or transverse beam test

461 measures behavior of brittle materials (usually with a rectangular cross section) by applying

462 vertical load in which tensile stress produced on the convex side of the specimen and

463 compression stress in the concave side. The load is applied on either one point (3 point bending)

464 or two points (four-point bending) and the specimen deflection is measured by the crosshead 
465 position. The bending test provides values for the modulus of elasticity in bending $\left(\mathrm{E}_{\mathrm{f}}\right)$, flexural 466 stress $\left(\sigma_{\mathrm{f}}\right)$, flexural strain $\left(\epsilon_{\mathrm{f}}\right)$ and the flexural stress-strain response of the material. Usually, the 467 3-point bending test is applied to polymers and the values like flexural strength and flexural 468 modulus are reported. Flexural strength is defined as the maximum stress in the outermost fiber, 469 the modulus of rupture is defined as the stress at fracture in bending and the flexural modulus is 470 the slope of the stress-deflection curve $[78,79] . \underline{\text { Hardness, }}$ which is defined as the resistance to 471 permanent indentation, is an indicator of the strength of a material and its resistance to scratching 472 or wear. The resistance to indentation depends on the shape of the indenter and the applied load; 473 therefore, several hardness test methods have been developed to measure the hardness of a 474 material, including Brinell test (using a steel or tungsten-carbide ball indenter [80]), Rockwell 475 test (using a diamond cone or steel ball indenter [81]), Vickers test (using a diamond pyramid 476 indenter), Knoop test (using a diamond pyramid indenter) and Scleroscope and Leeb test (using a 477 diamond-tipped indenter) $[75,81]$. Impact tests measure the ability of a specimen to resist high478 rate loading and it is used for determining the energy absorbed in fracturing a test specimen at 479 high velocity which is important for estimating the service life of a test piece. Typically, this test 480 is performed by placing a notched specimen in an impact tester (supported at both ends in 481 Charpy test, or at one end in Izod test) and breaking it with a swinging pendulum. In brittle 482 materials, less energy is required for starting a crack, and a little more to propagate it to the 483 shattering climax [75]. Dynamic mechanical, thermal analysis (DMTA) is another technique frequently 485 employed to characterize the viscoelastic properties of polymers, in which a sinusoidal stress is 486 applied to the specimen and the resulting displacement (strain) is measured. Properties such as 487 storage modulus, loss of modulus, lag phase (between stress and strain) and glass transition 
488 temperature can be measured with this technique [82]. The storage modulus, which measures the 489 stored energy, represents the elastic characteristic of a polymer. The storage modulus G' is 490 related to the molecular packing density in the glassy state $[56,57]$ and higher $G^{\prime}$ means the 491 better mechanical properties. The $\mathrm{G}^{\prime}$ is decreasing upon elevated temperatures when the polymer 492 chain is in the rubbery plateau region [54] due to the free movements of the polymer chains. The 493 loss modulus, G', measures the energy dissipated as the heat and represents the viscous part. 494 Generally, smaller G" suggests better mechanical properties and the strong tendency for 495 reversibility in the samples [54]. At the glass transition temperature, $T_{g}$, the $G^{\prime}$ decreases 496 dramatically while G” reaches its maximum. Temperature sweep tests, frequency sweep tests and 497 dynamic stress-strain tests are the most common test modes employed for characterizing the 498 viscoelastic properties of polymers in DTMA studies. Thermogravimetric analysis (TGA), is a technique currently employed for measuring 500 changes in physical and chemical properties versus temperature (constant heating rate mode) or 501 time (constant temperature or mass loss mode). As the temperature increases, various 502 components of the sample decomposed. Commonly, in TGA, the percentage of weight loss or 503 the rate of weight loss would be presented versus temperature, which are referred to as the 504 thermogravimetric curve and the differential thermogravimetric curve, respectively [83]. For 505 thermosets, TGA can provide information about the thermal stability, loss of volatiles, 506 decomposition rate and oxidation-reduction reactions and it is employed to study of degradation 507 mechanisms and reaction kinetics [84]. The degradation in thermoset systems starts with 508 decomposition of the crosslinked network and follows by the random scission of the linear 509 chains [85]. 


\subsection{Rheological properties and curing kinetics of the star-shaped resins}

Viscosity of the resins: Inadequate and poor impregnation of a viscous matrix to fibers is a major problem in composite manufacturing. It makes the production process to be slow and also reduce the mechanical strength of the product $[12,13]$. The resistance to flow of a liquid is expressed in terms of the viscosity. The viscosity is of importance for manufacturing processes, maximizing the production efficiency, improving processability as well as for improving the impregnation efficiency of the matrix to the reinforcement fiber for composite production [86]. It is believed that the linear PLA shows a long Newtonian plateau typical of polymers having a linear chain structure (at low to moderate oscillation frequencies <100 rad/sec). For the S-LA systems however, a Non-Newtonian behavior has been reported. Also, the S-LA systems show an intensified shear thinning response (similar to comb-like PLA) compared to the linear PLA [87]. In composite manufacturing industry, low viscosity of thermoset resin is a crucial factor for several processing methods, including vacuum infusion, spray and hand lay-up, filament winding, and pultrusion [8]. The solution and melt rheological properties of linear PLA have been studied intensively in the literature and a proportional relationship between the MW and the viscosity has been reported [87-89]. Comparably lower viscosities of thermosets, suggest better processability and better impregnation in these systems and make thermosets desirable as a matrix for reinforced composite applications. Generally, the lower the viscosity, the better rheological properties and more desired matrix to be used for reinforced composite applications [90]. For a satisfactory composite manufacturing, Li et al., suggests that the resin flow viscosity needs to be below 5 Poise $(0.5 \mathrm{~Pa} \mathrm{~s})$ [91]. It is believed that employing a core molecule in the structure of oligomers can reduce the viscosity of the resins. This reduction can be ascribed to the coiling character of polymers [73]; therefore, as the star-shaped polymers have smaller hydrodynamic volume compared to that of linear polymers with the same molecular weight, the 
534 viscosity will be lower $[15,56]$. However, the contradictory observations have also been reported

535

536

537

538

539

540

541

542

543

544

545

546 LAs.

547

548

Table 2. The effect of the core molecule and the LA chain length on the viscosity of the S-

\begin{tabular}{lllllll}
\hline Core molecule & $\begin{array}{l}\text { LA Chain } \\
\text { length }\end{array}$ & End-functionalization & $\begin{array}{l}\text { Number } \\
\text { of } \\
\text { branches }\end{array}$ & $\begin{array}{l}\text { Viscosity at } \\
25^{\circ} \mathrm{C} \mathrm{Pa} \text { s }\end{array}$ & $\begin{array}{l}\text { Viscosity min } \\
\text { Pa. s }\end{array}$ & Ref \\
\hline Unsaturated polyester & - & none & - & 0.3 & 0.1 at $70^{\circ} \mathrm{C}$ & {$[6]$} \\
\hline xylitol & 3 & MAAH & 5 & 2.97 & 0.06 at $85^{\circ} \mathrm{C}$ & {$[52]$} \\
\hline pentaerythritol & 5 & IT-MAAH & 4 & 7000 & 4 at $80^{\circ} \mathrm{C}$ & {$[8]$} \\
\hline glycerol & 3 & MAAH & 3 & 1.09 & 0.04 at $100^{\circ} \mathrm{C}$ & {$[4]$} \\
\hline glycerol & 7 & MAAH & 3 & 80 & 0.33 at $100^{\circ} \mathrm{C}$ & {$[4]$} \\
\hline glycerol & 10 & MAAH & 3 & 900,000 & 1.05 at $100^{\circ} \mathrm{C}$ & {$[4]$} \\
\hline pentaerythritol & 5 & MAAH-Allyl alcohol & 4 & 0.02 & 0.01 at $70^{\circ} \mathrm{C}$ & {$[6]$} \\
\hline
\end{tabular}

Curing kinetics: Curing involves the irreversible transformation of low molecular weight

550 oligomers into a solid network. Thermal curing of thermosets consists of the heating period stage

551 and the curing reaction stage. During the heating period, the resin is heated up to a temperature at

552 which the curing reaction starts, while in the curing reaction stage, the heat evolved from the 
553 overall curing mass at a constant temperature [57]. Often, in the S-LA thermosets, curing

554 reaction starts by the assistance of a radical initiator. The tuning of curing parameters, including

555 temperatures, pressures, time, etc. [90] is of importance, especially in thermosets, as it affects the

556 properties of the final product and applying improper conditions for curing, may result in higher

557 exotherms, faster gelation and more shrinkage due to excessive thermal zoning [52, 60].

558 Understanding of the cure process is substantially important, especially for more complex

559 systems such as industrial formulations, as a variety of additives are interfering in the curing

560 procedure, resulting in a more complex cure kinetics. These factors indicate that an excellent

561 control over curing process is required for production of thermosets with desired properties [70,

562 71]. The cure process can be evaluated based on two methods: a) monitoring the changes in

563 concentration of the reactive groups and b) by monitoring the changes in the physiomechanical

564 properties of the sample [71]. Cure kinetics correlate heat release rate (HRR) with the

565 temperature (or time) and the resultant degree of cure [90]. The analytical models of cure

566 kinetics have wide applications in numerical simulations of composite manufacturing processes.

567 Phenomenological -also called empirical- modeling approach is commonly employed for the

568 analytical expression of the cure kinetics based on an Arrhenius type equation in which the

569 approximated relationship of the curing parameters of the mathematical model are compared

570 with the experimental data [90]. Several phenomenological models are presented in the literature

571 for modeling the curing kinetics of the thermosetting resins; however, a few studies are

572 performed for the modeling the curing kinetics of the S-LAs [56, 90]. The degree of cure, $\alpha$,

573 presents the extent of the curing reaction and is proportional to the amount of heat released by

574 bond formation. The degree of cure is defined as:

$$
\alpha=\frac{H}{H_{u}}
$$


where $H$ is accumulative reaction heat up to time $t$, and $H_{u}$ is the total heat released during curing

reaction. $H_{u}$ is evaluated by

$$
H_{u}=\int_{0}^{t_{f d}}\left(\frac{d Q}{d t}\right)_{d} d t
$$

where $t_{f d}$ is the total reaction time and $(\mathrm{dQ} / \mathrm{dt})_{\mathrm{d}}$ is the instantaneous heat flow during the dynamic scanning. The curing rate which is proportional to the rate of heat generation, is defined as:

$$
\frac{d \alpha}{d t}=\frac{1}{H_{u}}\left(\frac{d H}{d t}\right)
$$

Table 3 provides a summary of suggested phenomenological models in the literature.

Table 3, phenomenological models suggested for curing kinetics of the thermosetting

\begin{tabular}{|c|c|c|c|c|}
\hline Model & Equation & Parameters & Dependent parameters & Ref \\
\hline nth- order rate & $\frac{d \alpha}{d t}=K(1-\alpha)^{n}$ & $\begin{array}{l}K: \text { reaction rate constant } \\
K=K_{0} \exp \left(-\frac{\Delta E_{A}}{R T}\right)\end{array}$ & $\begin{array}{l}K_{0}: \text { Arrhenius frequency factor } \\
\Delta E_{A}: \text { activation energy } \\
\mathrm{R}: \text { universal gas constant } \\
\mathrm{T}: \text { absolute temperature }\end{array}$ & {$[92]$} \\
\hline Autocatalytic & $\frac{d \alpha}{d t}=K \alpha^{m}(1-\alpha)^{n}$ & $\begin{array}{l}\mathrm{K} \text { : reaction rate constant. } \\
K=K_{0} \exp \left(-\frac{\Delta E_{A}}{R T}\right) \\
\text { m, n: reaction orders defined by } \\
\text { experimental data. }\end{array}$ & $\begin{array}{l}K_{0}: \text { Arrhenius frequency factor } \\
\Delta E_{A}: \text { activation energy } \\
\mathrm{R}: \text { universal gas constant } \\
\mathrm{T}: \text { absolute temperature }\end{array}$ & [93] \\
\hline Kamal & $\frac{d \alpha}{d t}=\left(K_{1}+K_{2} \alpha^{m}\right)(1-\alpha)^{n}$ & $\begin{array}{l}\text { Ki: reaction constants. } \\
\qquad K_{i}=K_{i 0} \exp \left(-\frac{\Delta E_{i}}{R T}\right), \quad(i=1,2) \\
\text { m, n: reaction orders defined by } \\
\text { experimental data. }\end{array}$ & $\begin{array}{l}K_{i 0}: \text { Arrhenius frequency } \\
\text { factors. } \\
\Delta E_{i}: \text { activation energy } \\
\text { R: universal gas constant } \\
\text { T: absolute temperature }\end{array}$ & [94] \\
\hline $\begin{array}{l}\text { Modified } \\
\text { Kamal }\end{array}$ & $\frac{d \alpha}{d t}=\left(K_{1}+K_{2} \alpha^{m}\right)\left(\alpha_{\max }-\alpha\right)^{n}$ & $\begin{array}{l}\text { Ki: reaction constants. } \\
\qquad K_{i}=K_{i 0} \exp \left(-\frac{\Delta E_{i}}{R T}\right), \quad(i=1,2) \\
\text { m, n: reaction orders defined by } \\
\text { experimental data. } \\
\alpha_{\text {max }}: \text { maximum degree of cure at a } \\
\text { given temperature }\end{array}$ & $\begin{array}{l}K_{i 0}: \text { Arrhenius frequency } \\
\text { factors. } \\
\Delta E_{i}: \text { activation energy } \\
\mathrm{R}: \text { universal gas constant } \\
\mathrm{T}: \text { absolute temperature }\end{array}$ & {$[90]$} \\
\hline Cole & $\frac{d \alpha}{d t}=\frac{K \alpha^{m}(1-\alpha)^{n}}{1+e^{C\left(\alpha-\left(\alpha_{c 0}+\alpha_{C T} T\right)\right)}}$ & $\begin{array}{l}K \text { : reaction rate constant. } \\
K=K_{0} \exp \left(-\frac{\Delta E_{A}}{R T}\right) \\
m, n \text { : reaction orders defined by } \\
\text { experimental data. } \\
\text { C: diffusion constant. } \\
\alpha_{c 0}: \text { critical degree of cure at } \mathrm{T}=0 \mathrm{~K} \text {. } \\
\alpha_{C T}: \text { increase in critical resin degree of } \\
\text { cure with temperature. }\end{array}$ & $\begin{array}{l}K_{0}: \text { Arrhenius frequency factor } \\
\Delta E_{A}: \text { activation energy } \\
\mathrm{R}: \text { universal gas constant } \\
\mathrm{T}: \text { absolute temperature }\end{array}$ & {$[95]$} \\
\hline
\end{tabular}
systems.

The nth- order rate equation is the simplest phenomenological model proposed for predicting the rate of the curing reaction in thermosets. The nth-order reaction predicts the maximum curing rate at the beginning of the curing phenomenon and does not account for the 
585 autocatalytic effect [92]. The autocatalytic models represent the autocatalytic effect of the curing

586 reactions. This model considers a single rate constant for the reaction and the maximum reaction

587 rate is supposed to take place in the intermediate conversion stage. A more accurate model has

588 been proposed by Kamal and Sourour considering two rate constants for the curing kinetics

589 (known as Kamal's model) [93, 94]. However, more parameters in the model have made the

590 model to be more complicated. The limitation of all the mentioned models is that they are just

591 valid when the kinetic of bond formation, is considered to be the only rate controlling step in the

592 curing reactions. The vitrification effect (transforming to a non-crystalline amorphous solid) has

593 been considered in a modified version of Kamal's model in which the fractional conversion has

594 been considered to not exceed the degree of cure associated with vitrification. In the Cole's

595 model, another controlling mechanism for the curing is considered in expressing the curing

596 kinetic equation. This diffusion constant term in the equation, explicitly accounts for shifting

597 from the kinetics to the diffusion control $[90,95]$.

598 4. Applications

$599 \quad \underline{4.1}$ Biocomposites

600

Composites are engineered materials with wide range of applications, which are currently

601 produced from petroleum based resins and synthetic fibers. Polymers are of the common

602 matrices which are used for fiber reinforced plastics. The matrix material determines the overall

603 durability of the composites as well as the shape, surface appearance and the environmental

604 tolerance of the final product. The fibrous reinforcement role is to carry the structural loads while

605 provides macroscopic stiffness and strength to the composites [96-98]. Increasing attentions

606 toward sustainable development, concerns about petroleum resources and economic and

607 environmental issues have led to many attempts toward replacing the petroleum based materials 
608 with the renewable substitutes. Developments in emerging biobased thermosets are spectacular 609 from a technological point of view. Use of biobased materials and natural fibers not only 610 contributes to the production of a more environmentally friendly product, but also has 611 advantages such as low weight and low manufacturing costs [99, 100]. Different biobased raw materials have been suggested for the production of composites.

613 Versatile and economical renewable sources make LA a suitable source for production of 614 thermoplast bioplastics $[17,29,101]$. Thermoplasts are a class of polymers with high molecular 615 weight, in which the chains are associated through intermolecular forces. Thermoplasts' structure 616 is weaken rapidly upon temperature increase. In contrast, thermosets form chemical bonds during 617 the curing process and the structure cannot be reformed upon further heating-cooling processes $618[102,103]$. Limitations in impregnation of the matrix to fibers, make the thermoplast processing 619 to be slow and costly and also reduce the mechanical strength of the produced composites [102, 620 104]. In addition, PLA's hydrophobic nature makes it incompatible with natural fibers [105621 107], thus, hydrophilic fibers cannot be efficiently employed for reinforcing the PLA matrix [29, 622 104]. From the other hand, thermosets bestow a lower viscosity which results in the better 623 processability and better impregnation of fibers which consequently makes thermosets desirable 624 to be used as the matrix for reinforced composite applications $[90,103]$. The other privilege of 625 the thermoset systems over thermoplasts is that thermosets can be tailored for a certain 626 functionality by altering the chemical structure or by changing the crosslinking density [108]. 627 However, there are also several disadvantages associated with the current thermosetting resins, 628 e.g. environmental issues, nonrenewable expensive sources and the poor thermomechanical and 629 impact properties [108]. 
Inexpensive biobased raw material, better environmental profile, low viscosity and better 631 processability of the matrix along with better thermomechanical properties of the produced

632 biocomposites are of advantages expected for the S-LA composites. So far, composites of S-LA 633 matrix and different reinforcements, including viscose fiber [59], flax fibers [6, 7] and basalt [6] 634 have been produced. Hypothetically, unsaturated branches of the core molecule increase the 635 hydrophilicity of the produced resin and make it more compatible with inexpensive natural fibers 636 which eventually increases the mechanical properties and lower the final costs of the 637 biocomposites. However, sometimes a hyper branched core molecule in the structure of the S638 LA thermoset can adversely affect the thermomechanical properties, and also it is plausible that 639 unsaturated groups available in the core molecule of the polymer affect the water absorption 640 capacity of the matrix which results in altering the electrical and physiochemical properties of 641 the product.

\section{$642 \quad \underline{4.3}$ Biomedical}

Polymers are currently employed in a wide range of biomedical applications, including

644 drug delivery, tissue engineering, scaffold fabrication and gene delivery. Drug delivery is the 645 method of transporting a pharmaceutical compound in the body to achieve a desired therapeutic 646 effect. Biodegradable polymeric systems have been extensively studied for controlled release 647 formulations and drug-targeting systems in forms of microspheres, films, tablets, or 648 implantation devices, almost for two decades [72]. Wide diversity in the topology and the 649 chemistry, ease of formulation for various devices, excellent bio-compatibility, biodegradability 650 and mechanical strength have introduced a class of FDA approved aliphatic polyesters such as

651 PLA, PGA, and PLGA to be used in controlled release of drugs, especially for cancer therapy $652[39,63,69,72,109]$. Tissue engineering aims to apply engineering methods to create artificial 
653 substitutes for defective tissues and organs $[110,111]$. In tissue engineering, specific cells are

654 isolated from the patient and cultivated on a 3D biomimetic scaffold under controlled conditions.

655 The construct is often implanted in the desired site of the patient's body, allowing the new tissue

656 formation into the scaffold which is degrading over time [110]. The matrix can be served as a

657 substrate for attachment, grow and migration of cells or can be utilized as a drug carrier to

658 activate cellular function in the region $[110,112]$. Biodegradable polymers, by providing 659 exogenous matrices suitable for facilitating tissue regeneration, play an important role in most 660 tissue engineering strategies [113].

Drug delivery: It is believed that the architecture of the polymer, called topology, often

662 influences the physicochemical properties and effects the microsphere preparation and drug 663 delivery properties [3, 69]. The polymer architectures plays a crucial role in the drug delivery 664 control and in the fabrication of drug delivery systems; however, it is relatively unfamiliar to 665 pharmacists. Different polymer topologies have been studied for drug delivery, which can be 666 categorized in to linear, branched, cross-linked, block, star-shaped and dendrimer topology [69].

667 Star-shaped polymers are a class of branched polymers with a 3D hyperbranched structure and 668 linear arms, in which branching occurs via controlled polymerization techniques [1, 69]. 669 Compared to linear polymers with the same composition and MW, the star-shaped polymers 670 provide smaller hydrodynamic radius and so, a lower solution viscosity. In the S-LA structure,

671 the employ of higher molecular weights of PEG in the structure of PLA-PEG is possible due to 672 the presence of the core molecule which is an important factor in designing a system with high 673 control over the hydrophilic/hydrophobic balance and core protection [69]. The star-shaped 674 polymers can be synthesized via arm-first or core-first methods. In the arm-first methods, the 675 linear arms are prepared via a controlled polymerization pathway; then, the chains are reacted 
676 with multifunctional terminating agents. The core-first method which is the dominant employed

677 technique, provides a better control over the process and starts with a multifunctional initiator

678 and the propagation of the arms through a controlled polymerization pathway. Research on S-LA

679 polymers as drug vectors seem rather limited so far; however, different initiators, or core 680 molecules have been studied so far for the drug delivery purposes, including, PEG [38], THMP $681[16,48]$, PENTA [51], di(trimethylolpropane) [48], cholic acid [65] and luminescent ruthenium 682 tris(bipyridine) [2].

Tissue engineering: Successful utilization of biomaterials for tissue engineering is dependent on several factors. The biomaterial must resorb after its service and should provide 685 conditions for sufficient growth rate and effective cell adhesion, while it is -or its degradation 686 materials are- nontoxic, when implanted in vivo. The material which is designed for tissue 687 engineering should also meet certain physical properties, including but not limited to having a) 688 high porosity ( $\leq 90 \%$ for providing enough surface area in a 3D structure), b) minimum 689 diffusional constraints (sufficient to meet the metabolic requirements), c) sufficient space for 690 extracellular matrix regeneration and d) adjustable degradation rate (to match the rate of tissue 691 regeneration in vivo) $[114,115]$. The microarchitecture of the device is also of importance as it 692 influences the interconnection between the pores for cell proliferation. In addition, as scaffolds 693 are subjected to remain in intimate contact with the cells for prolonged periods, the influence of 694 the polymeric materials on viability, growth, and function of the attached or adjacent cells is of 695 crucial importance [116]. Different biodegradable polymers, including PLA, polylactide, 696 polyglycolide and PLG have been employed for cell transplantation or for various tissue 697 regeneration, including bone, cartilage, liver, and skin [113, 115]. The mechanical strength and 698 the rate of degradation of the PLG is typically adjusted based on the ratio of lactic to glycolide 
and polymer's degree of polymerization. Although the polymer blends must be well optimized by refining their properties to be used for tissue engineering, yet, polymer properties are not the only crucial factors in tissue engineering. The interaction of the cells with the surface of the polymer is another crucial factor and polymers that allow surface modification like PLG are particularly promising for tissue engineering purposes [117].

\section{$\underline{\text { 5. Perspectives, opportunities and limitations }}$}

\subsection{Perspectives and opportunities}

Substitution of current petroleum-based platforms with renewable-based technologies would be beneficiary in different ways. First, using the corn-based LA instead of conventional petroleum based monomers, will reduce the dependency of the national thermosetting plastic industry to the petroleum resources. Thus, in the long term, it will enhance the national energy security. Second, compared to petroleum based products, using biobased materials will substantially promote the environmental profile and sustainability of the production chain. In addition, the biodegradability of the products will alleviate carbon footprint and the environmental burdens associated with the final product. Third, using corn-based LA and inexpensive natural fibers as the raw materials, will subsequently promote economic diversification in rural areas. It has been shown that the S-LAs are capable of competing with or even surpassing fossil fuel based resins in terms of cost and eco-friendliness concerns [4, 6, 7, $12,52]$.

Modifications for biomedical use: Using a core molecule with adjustable functional groups at the center of the S-LA provides the unique opportunity of designing and controlling over properties of the resin. It is presumed that more hydroxyl groups of the core molecule, provide a better extended network to the final product. The unsaturated hydroxyl groups of the 
722 core molecule ultimately increase the hydrophilicity of the produced resin which make the resin

723 more compatible with hydrophilic systems. The privilege of these thermoset systems over other

724 systems is that these resins can be engineered for a certain functionality by changing the

725 chemical structure or altering the crosslinking density. Moreover, by changing the nature and the

726 portion of the block units of copolymers chain, it is possible to further manipulate the polymers

727 properties. This manipulation could be in terms of changing the hydrophilicity properties as well

728 as designing and manipulation of the void sizes of the polymer network. By employing longer

729 arms which will act as plasticizers, it is possible to increase the size of the voids in the network

730 and by using hydrophilic monomers in copolymers the hydrophilicity of the polymer network

731 can be tailored. Manipulation of both void sizes and the hydrophilicity of voids will provide the

732 unique opportunity for designing a polymeric matrix which is specifically designed for certain

733 chemical component release or a desired drug delivery -based on drugs chemical structure,

734 molecular weight, polarity, etc. with a substantial control over the release rate. In these systems,

735 the polymer network can be tailored based on different parameters, including substitution of LA

736 hydrophobic groups with a more hydrophilic group such as glycolic acid, by changing the ratio

737 of the chain extender to the oligomer units or by changing the cross-linking density of the cured

738 thermoset system. Using short oligomer chains in the network of the polymer leads to a compact

739 network structure results in more resistance on diffusion. In addition, by reducing the ratio of

740 methyl groups to the carbonyl groups in the structure (which results by applying higher ratios of

741 glycolic acid units to lactic ones in the PGLA polymer), more hydrophilic structure is achieved.

742 Smart packaging applications: The S-LA thermosets provide an adjustable polymeric

743 network, which potentially can be tailored for active packaging of productions. Active packaging

744 (also called intelligent or smart packaging), means having active functions beyond the inert, 
745 passive containment and protection of the product and refers to packaging systems currently 746 employed for foods, pharmaceuticals, and several other types of products [118, 119]. Nowadays, 747 PLA is employed as an active packaging material for antibacterial packaging with the ability of 748 controlled release of antimicrobial or antioxidant compounds. Antioxidant packaging is a well749 known, promising technique for increasing food quality and extending food production shelf life 750 [119]. The addition of antioxidants to the polymeric packages has two facets. First, available 751 antioxidants in the polymer formulations protect the ester bonds of the polymer structure from 752 degradation $[19,120,121]$. Second, it helps protecting the food contents by migration of 753 antioxidants from packaging material to the food medium. It is believed that antioxidant 754 compounds can defuse and migrate from the packaging material to the food product and help 755 maintaining the quality of the food. Previously, antioxidants have been successfully incorporated 756 into different polymeric matrices, including low density polyethylene (LDPE), polyvinyl 757 chloride (PVC) and polypropylene (PP), for various foods [122-124]. The release of 758 antioxidants is a result of the biodegradation of the polymer matrix as well as the diffusion 759 phenomenon. In the diffusion of antioxidants, the migrant diffuses through the polymer matrix 760 toward the interface and then partitioned between the polymer matrix and the food medium until 761 the equilibrium. Therefore, antioxidant release can be presented as a result of diffusion, 762 dissolution and finally, the equilibrium process [124, 125].

764 of fire hazards and to pass safety specifications in polymers. A flame retardant additive reduces 765 the flammability of the product and the smoke generation capability [126, 127]. In the S-LA 766 systems, the flame-retardancy feature can be potentially obtained by adding the phosphorus 767 containing groups (or other flame retardant groups) to the structure of the network. In these 
systems, the core molecule provides different reactive sites (hydroxyls) which may be employed

769 for addition of a special functionality. The other sites which may be used to add a functional

770 group, are the chains. In addition, using an EF agent with groups containing a flame retardant

771 component, can add flame retardancy feature to the S-LA thermosets.

\section{$772 \quad$ 5.2. Gaps and limitations}

773

In this section, shortcomings and gaps of S-LA systems are discussed. S-LA and their

774 composites have been synthesized and employed for several applications for decades. Employing

775 a core molecule makes the structure of these systems more complex compared to linear

776 thermoplast PLA. Moreover, the combination of different polymerization steps, EF reactions and

777 curing reactions have imposed more complexity to these systems. In addition, numerous

778 applications are considered for these systems, including biomedical applications, adhesives,

779 coatings and biocomposites, and each certain application requires certain characteristics. In order

780 to manipulation of the S-LA for a specific desired property, these systems must be thoroughly

781 characterized. Shortcomings and gaps in the different steps must be well studied. The aim of the

782 following section is to discuss drawbacks associated with different steps of preparation and

783 characterization of these systems. These gaps are classified into two categories: the synthesis and

784 manufacturing concerns and the characterizing issues.

Generally, using a chain extender imposes more complexity to the system which

786 inevitably leads to a comparably poor control over the polymerization. The choice of the core

787 molecule would be one of the most important factors. It can directly effect on the crosslinking

788 density, mechanical properties, thermostability, degradation rate and the hydrophobicity of the

789 system. The ratio of the core molecule to the LA monomers is another important factor which

790 affects the crosslinking density and the final properties of the produced network. Too much core 
791 molecule makes the resin brittle and reduces the diffusion rates. The thermostability of the core

792 molecule is of importance, as the synthesis often occurs at high temperatures and molecules with

793 susceptible bonds can be degraded during the synthesis. Steric hindrance, increased by

794 employing the core molecules with multi-hydroxyl branches and may result in an incomplete

795 reaction of branches with the hydroxyl groups which leaves unsaturated sites in the core

796 molecule. Even if the complete reaction of hydroxyl groups ensured, still the length of chains

797 might vary between oligomers which results in unpredictable mechanical and diffusional

798 properties for the batch to batch resins. This is problematic, especially when the resin is expected

799 to be used for the drug delivery and biomedical applications. In addition, the polycondensation

800 synthesis pathway, which is commonly employed for the synthesis of the S-LAs, is an energy

801 extensive step, due to the long reaction times at high temperatures. It also requires large

802 quantities of organic solvents for effective water removal which must be recycled through the

803 azeotropic condensation. This purification and water removal step imposes a substantial

804 environmental load. Thus, there is a need for optimization of the required energy for the

805 synthesis. The energy inputs can be alleviated by optimization of the process and choosing more

806 effective solvents, more efficient catalyst systems or choosing an alternative synthesis method.

807 The EF reaction is the other important synthesis step. Despite the condensation step, the EF

808 reactions occur at moderate temperatures and shorter reaction durations. However, this step

809 requires a crucial control over the temperature as at elevated temperatures, the undesired partial

810 crosslinking happens and the risk of gelation is increased. In this step, in order to avoid unwanted

811 crosslinking, an inhibitor agent often used for protecting the olefinic carbon bonds. The origin of

812 the EF agents, the presence of releasing products during the reaction, e.g. MAA, the progress of

813 EF reactions and the degradation products are of other concerns, especially when the cured resin 
814 is intended to service in-vivo in biomedical applications. The optimization of the EF reactions

815 would be a tackle as applying insufficient reaction times and temperatures result in poor 816 crosslinking density and subsequently inferior mechanical properties of the product, and 817 applying excess reaction times and elevated temperatures increase the risk of gelation. Therefore, 818 successful substitution of the nonrenewable EF agents with nontoxic renewable ones is of 819 interest. The rheological properties of these systems are the other hotspot. The rheological 820 properties of the S-LA systems have not been studied intensively in the literature. Although 821 employing a core molecule in the structure of oligomers is believed to reduce the viscosity of the 822 resins $[15,56]$, yet, resulted viscosities are still far from the desired viscosity for manufacturing 823 processes. It is believed that a proportional relationship exists between the MW and the viscosity 824 of these systems [87-89]. Employing core molecules with fewer hydroxyl groups, reduction in 825 the LA chain length of branches and an efficient functionalization of the remaining hydroxyl 826 groups can further reduce the viscosity of resins. The curing procedure is also of importance and 827 must be well optimized as it can affect the properties of the final product. Applying improper 828 curing techniques result in undesired mechanical strength on the matrix [128]. Different factors 829 are involved in the free radical curing reactions which are often employed for curing of the S-LA 830 systems, including the nature of the initiator, initiator: resin ratio, applied heat regimes, retention 831 times and cooling strategies. Using excess curing agent or applying high temperatures for the 832 curing may result in higher exotherms, faster gelation and more shrinkage due to excessive 833 thermal zoning $[52,60]$.

835 Currently, the titration method is employed for monitoring the progress of the polycondensation 836 step which is based on TAN measurements titration of available acidic groups. The samples are 
837 diluted in the predefined solvent systems, capable of dissolving the S-LA, and then titrated with

$838 \mathrm{KOH}$. However, these solvent systems have been optimized for petroleum based materials and

839 might not be capable of efficient dissolving of the high MW oligomers of the S-LA which results

840 in unrealistic high conversion degrees. In addition, comparably more complex structure of these

841 systems makes the interpretation of the FT-IR and NMR analysis to be hard. Therefore, too

842 many peaks often can be found in the spectrums, especially in the carbonyl area of the EF resins,

843 which can obscure the results and make them very hard to interpret. In addition, these techniques

844 provide no solid information about the degree of completion of the polycondensation and EF

845 reactions.

\section{6. Conclusions}

847 The need for designing polymers for a certain application and the shortcomings associated 848 with the conventional synthesis methods, encouraged researchers to explore for the alternative 849 PLA synthesis routes. Utilization of chain extenders is a promising way to achieve a high MW 850 polymer capable of being engineered for a certain functionality. It is well known that changing

851 the architecture of the linear PLA would change its properties. The concept of using star-shaped 852 resins for biocomposites or in biomedical applications is gaining more and more attention day by 853 day. The polymer architecture is a crucial factor for the drug delivery control; however, it is 854 relatively unfamiliar to pharmacists. Employing a multifunctional core molecule at the center of 855 the S-LA systems, provides the unique opportunity of designing and controlling over release 856 properties of the resin. Adjustable structure of these aliphatic polyesters, provides the chance for 857 altering the chemistry, ease of formulation, excellent bio-compatibility and biodegradability and 858 makes them a suitable candidate for the controlled release of drugs, especially in cancer therapy. 859 In addition, altering the linear structure of the PLA, often results in lower viscosity, better 
extended network and better thermomechanical properties. Comparably lower viscosities of the S-LA thermosets, results in better processability and better impregnation of the matrix to the reinforcing fibers which is beneficiary for the composite applications. It is believed that often unreacted hydroxyl groups of the core molecule increase the hydrophilicity of the matrix and make it more compatible with hydrophilic natural fibers which results in the better mechanical properties of the biocomposites. However, in some cases, worse mechanical properties may result depending on the type of the employed core molecule. It is also plausible that unsaturated groups increase the water absorption capacity which results in altering the electrical and physiochemical properties of the matrix.

Developments in the emerging S-LA systems are spectacular from a technological point of view. However, these systems still suffer from different limitations and technological gaps and have a long way to go. These limitations can be categorized into the synthesis deficiencies and the characterization gaps. Firstly, employ of a core molecule makes the structure of these systems relatively more complex and reduce the control over the polymerization step. Association of multi-step reactions, including different polymerization steps, EF reactions and curing reactions also impose more complexity to these systems. The steric hindrance, increased by employ of the core molecule, may result in an incomplete reaction which leaves unsaturated hydroxyl groups in the network. Even if the complete reaction ensured, still the risk of inconsistent product remains as the length of chains cannot be efficiently controlled. The former results in the unpredictable mechanical and diffusion properties of the batch to batch product. The properties of the S-LA is dependent on several factors, including the molecular weight, the architecture of the network, rigidity of the core molecule, length of branches, crosslinking density and the degree of conversion. These interrelated factors, make the optimization and 
883 characterization to be complicated and hard. In addition, the type of the employed testing

884 methods depends on the expected service for the product. The tuning of the curing parameters is

885 also a challenge, especially for more complex systems such as industrial formulations. Applying

886 improper curing method results in inferior mechanical properties, higher exotherms, faster

887 gelation and more shrinkage in the cured resins. In addition, the polycondensation synthesis is

888 known as an energy extensive step. Large quantities of organic solvents required also impose

889 substantial environmental load. This is a very exciting period in the development of

890 biocompatible polymers, in particular, biobased S-LA resins. Although these state of the art,

891 adjustable S-LA systems look very interesting and promising for various applications, yet their

892 usage is limited. Therefore, future use of these systems requires systematic optimization and

893 invention of better characterization methods.

894

895

7. Acknowledgement

896 The authors would like to acknowledge the funds provided by Agricultural Experiment

897 Station, South Dakota State University and North Central Sun Grant through US Department of 898 Agriculture, Washington, DC in support of this research work. The authors also appreciate the 899 critical evaluation of biomedical part of this manuscript by Dr. Asma Rashki of School of 900 Medicine, Tehran University of Medical Sciences. 


\section{References:}

902

903

904

905

906

907

908

909

910

911

912

913

914

915

916

917

918

919

920

921

922

923

924

925

926

927

928

929

930

931

932

933

934

935

936

937

938

939

940

941

942

943

944

945

1. Takamura, M., et al., Effect of type of peroxide on cross-linking of poly (l-lactide). Polymer Degradation and Stability, 2008. 93(10): p. 1909-1916.

2. Wang, Y., et al., Rheological and topological characterizations of electron beam irradiation prepared long - chain branched polylactic acid. Journal of Applied Polymer Science, 2011. 122(3): p. 1857-1865.

3. Wolf, F.K. and H. Frey, Inimer-promoted synthesis of branched and hyperbranched polylactide copolymers. Macromolecules, 2009. 42(24): p. 9443-9456.

4. Bakare, F.O., et al., Synthesis and characterization of bio-based thermosetting resins from lactic acid and glycerol. Journal of Applied Polymer Science, 2014. 131(13).

5. Bakare, F.O., et al., Synthesis and characterization of unsaturated lactic acid based thermoset bio-resins. European Polymer Journal, 2015. 67: p. 570-582.

6. Bakare, F.O., et al., Thermomechanical properties of bio-based composites made from a lactic acid thermoset resin and flax and flax/basalt fibre reinforcements. Composites Part A: Applied Science and Manufacturing, 2016. 83: p. 176-184.

7. Åkesson, D., et al., Thermoset lactic acid-based resin as a matrix for flax fibers. Journal of Applied Polymer Science, 2011. 119(5): p. 3004-3009.

8. Åkesson, D., et al., Synthesis and characterization of a lactic acid-based thermoset resin suitable for structural composites and coatings. Journal of applied polymer science, 2010. 115(1): p. 480-486.

9. Zeng, X., et al., Cholic acid-functionalized nanoparticles of star-shaped PLGA-vitamin E TPGS copolymer for docetaxel delivery to cervical cancer. Biomaterials, 2013. 34(25): p. 6058-6067.

10. Kim, E.S., B.C. Kim, and S.H. Kim, Structural effect of linear and star-shaped poly (L-lactic acid) on physical properties. Journal of Polymer Science Part B: Polymer Physics, 2004. 42(6): p. 939-946.

11. Park, S.Y., et al., Micellization and gelation of aqueous solutions of star-shaped PLLAPEO block copolymers. Macromolecules, 2003. 36(11): p. 4115-4124.

12. Lin, Y. and A. Zhang, Synthesis and characterization of star-shaped poly (d, l-lactide)block-poly (ethylene glycol) copolymers. Polymer bulletin, 2010. 65(9): p. 883-892.

13. Lin, Y., A. Zhang, and L. Wang, Synthesis and characterization of star-shaped poly (ethylene glycol)- block-poly (L-lactic acid) copolymers by melt polycondensation. Journal of Applied Polymer Science, 2012. 124(6): p. 4496-4501. 
14. Sakai, R., et al., Fabrication of Polylactide-Based Biodegradable Thermoset Scaffolds for Tissue Engineering Applications. Macromolecular Materials and Engineering, 2013. 298(1): p. 45-52.

15. Finne, A. and A.-C. Albertsson, Controlled synthesis of star-shaped L-lactide polymers using new spirocyclic tin initiators. Biomacromolecules, 2002. 3(4): p. 684-690.

16. Biela, T., et al., Star-shaped poly (L-lactide) s with variable numbers of hydroxyl groups at polyester arms chain-ends and directly attached to the star-shaped coreControlled synthesis and characterization. Journal of Polymer Science Part A: Polymer Chemistry, 2005. 43(23): p. 6116-6133.

17. Lunt, J., Large-scale production, properties and commercial applications of polylactic acid polymers. Polymer Degradation and Stability, 1998. 59(1): p. 145-152.

18. Datta, R. and M. Henry, Lactic acid: recent advances in products, processes and technologies - a review. Journal of Chemical Technology and Biotechnology, 2006. 81(7): p. 1119-1129.

19. Jamshidian, M., et al., Poly- Lactic Acid: production, applications, nanocomposites, and release studies. Comprehensive Reviews in Food Science and Food Safety, 2010. 9(5): p. 552-571.

20. Madhavan Nampoothiri, K., N.R. Nair, and R.P. John, An overview of the recent developments in polylactide (PLA) research. Bioresource Technology, 2010. 101(22): $\mathrm{p}$. 8493-8501.

21. Hartmann, M.H., High Molecular Weight Polylactic Acid Polymers, in Biopolymers from Renewable Resources, D.L. Kaplan, Editor. 1998, Springer Berlin Heidelberg: Berlin, Heidelberg. p. 367-411.

22. Drumright, R.E., P.R. Gruber, and D.E. Henton, Polylactic acid technology. Advanced materials, 2000. 12(23): p. 1841-1846.

23. Xiao, L., et al., Poly (lactic acid)-based biomaterials: synthesis, modification and applications. 2012: INTECH Open Access Publisher.

24. Esmaeili, N. and S. Javanshir, Eco Friendly Composites Prepared from Lactic Acid Based Resin and Natural Fiber, in Högskolan i Borås/Ingenjörshögskolan (IH). 2013, University of Borås: University of Borås/School of Engineering, Sweden. p. 69.

25. Ajioka, M., et al., The basic properties of poly (lactic acid) produced by the direct condensation polymerization of lactic acid. Journal of Environmental polymer degradation, 1995. 3(4): p. 225-234. 
1005

1006

1007

1008

1009

1010

1011

1012

1013

1014

1015

1016

1017

1018

1019

1020

1021

1022

1023

1024

1025

1026

1027

1028

1029

1030

1031

1032

1033

1034

1035

26. Kricheldorf, H.R. and R. Dunsing, Polylactones, 8. Mechanism of the cationic polymerization of $L, L$ - dilactide. Die Makromolekulare Chemie, 1986. 187(7): p. 16111625.

27. Kurcok, P., A. Matuslonicz, and Z. Jedlinski, Anionic-polymerization as a tool in the synthesis of biodegradable polymers. JOURNAL OF POLYMER MATERIALS, 1995. 12(2): p. 161-174.

28. Ray, S.S. and M. Bousmina, Biodegradable polymers and their layered silicate nanocomposites: in greening the 21st century materials world. Progress in materials science, 2005. 50(8): p. 962-1079.

29. Garlotta, D., A Literature Review of Poly(Lactic Acid). Journal of Polymers and the Environment, 2001. 9(2): p. 63-84.

30. Gu, S., et al., Synthesis and characterization of biodegradable lactic acid-based polymers by chain extension. Polymer International, 2008. 57(8): p. 982-986.

31. Alward, D.B., et al., Effect of arm number and arm molecular weight on the solid-state morphology of poly (styrene-isoprene) star block copolymers. Macromolecules, 1986. 19(1): p. 215-224.

32. Kanaoka, S., M. Sawamoto, and T. Higashimura, Star-shaped polymers by living cationic polymerization. 1. Synthesis of star-shaped polymers of alkyl and vinyl ethers. Macromolecules, 1991. 24(9): p. 2309-2313.

33. Fukui, H., M. Sawamoto, and T. Higashimura, Multifunctional coupling agents for living cationic polymerization. 3. Synthesis of tri-and tetra-armed poly (vinyl ethers) with triand tetrafunctional silyl enol ethers. Macromolecules, 1994. 27(6): p. 1297-1302.

34. Dong, C.-M., et al., Synthesis of star-shaped poly (E-caprolactone)-b-poly (dl-lactic acidalt-glycolic acid) with multifunctional initiator and stannous octoate catalyst. Macromolecules, 2001. 34(14): p. 4691-4696.

35. Marsalko, T., I. Majoros, and J. Kennedy, Multi-arm star polyisobutylenes. Polymer Bulletin, 1993. 31(6): p. 665-672.

36. Lutz, P. and P. Rempp, New developments in star polymer synthesis. Star- shaped polystyrenes and star-block copolymers. Die Makromolekulare Chemie, 1988. 189(5): p. 1051-1060.

37. Kim, S.H., et al., Preparation of star-shaped polylactide with pentaerythritol and stannous octoate. Die Makromolekulare Chemie, 1993. 194(12): p. 3229-3236. 
1054

1055

1056

1057

1058

1059

1060

1061

1062

1063

1064

1065

1066

1067

1068

1069

1070

1071

1072

1073

1074

1075

1076

1077

1078

1079

1080

1081

38. Choi, Y.K., Y.H. Bae, and S.W. Kim, Star-shaped poly (ether-ester) block copolymers: synthesis, characterization, and their physical properties. Macromolecules, 1998. 31(25): p. 8766-8774.

39. Makadia, H.K. and S.J. Siegel, Poly lactic-co-glycolic acid (PLGA) as biodegradable controlled drug delivery carrier. Polymers, 2011. 3(3): p. 1377-1397.

40. Kumari, A., S.K. Yadav, and S.C. Yadav, Biodegradable polymeric nanoparticles based drug delivery systems. Colloids and Surfaces B: Biointerfaces, 2010. 75(1): p. 1-18.

41. Houchin, M. and E. Topp, Physical properties of PLGA films during polymer degradation. Journal of applied polymer science, 2009. 114(5): p. 2848-2854.

42. Cheng, J., et al., Formulation of functionalized PLGA-PEG nanoparticles for in vivo targeted drug delivery. Biomaterials, 2007. 28(5): p. 869-876.

43. Ghahremankhani, A.A., F. Dorkoosh, and R. Dinarvand, PLGA-PEG-PLGA tri-block copolymers as in situ gel-forming peptide delivery system: effect of formulation properties on peptide release. Pharmaceutical development and technology, 2008. 13(1): p. 49-55.

44. Jeong, B., Y.H. Bae, and S.W. Kim, In situ gelation of PEG-PLGA-PEG triblock copolymer aqueous solutions and degradation thereof. Journal of biomedical materials research, 2000. 50(2): p. 171-177.

45. Jeong, J.H., et al., Synthesis, characterization and protein adsorption behaviors of PLGA/PEG di-block co-polymer blend films. Colloids and Surfaces B: Biointerfaces, 2000. 18(3-4): p. 371-379.

46. Astete, C.E. and C.M. Sabliov, Synthesis and characterization of PLGA nanoparticles. Journal of Biomaterials Science, Polymer Edition, 2006. 17(3): p. 247-289.

47. Kricheldorf, H.R., H. Hachmann-Thiessen, and G. Schwarz, Telechelic and star-shaped poly (L-lactide) s by means of bismuth (III) acetate as initiator. Biomacromolecules, 2004. 5(2): p. 492-496.

48. Biela, T., et al., Characterization of star-shaped poly (L-lactide) $s$ by liquid chromatography at critical conditions. Polymer, 2003. 44(6): p. 1851-1860.

49. Helminen, A.O., H. Korhonen, and J.V. Seppälä, Structure modification and crosslinking of methacrylated polylactide oligomers. Journal of applied polymer science, 2002. 86(14): p. 3616-3624.

50. Perry, M.R. and M.P. Shaver, Flexible and rigid core molecules in the synthesis of poly (lactic acid) star polymers. Canadian Journal of Chemistry, 2011. 89(4): p. 499-505. 
51. Kim, S.H., et al., Multifunctional initiation of lactide polymerization by stannous octoate/pentaerythritol. Die Makromolekulare Chemie, 1992. 193(7): p. 1623-1631.

52. Jahandideh, A. and K. Muthukumarappan, Synthesis, characterization and curing optimization of a biobased thermosetting resin from xylitol and lactic acid. European Polymer Journal, 2016. 83: p. 344-358.

53. Biela, T., et al., Well-defined star polylactides and their behavior in two-dimensional chromatography. Journal of Polymer Science Part A: Polymer Chemistry, 2002. 40(16): p. 2884-2887.

54. Bakare, F.O., et al., Thermomechanical properties of bio-based composites made from a lactic acid thermoset resin and flax and flax/basalt fibre reinforcements. Composites Part A: Applied Science and Manufacturing, 2015.

55. Liu, K., S.A. Madbouly, and M.R. Kessler, Biorenewable thermosetting copolymer based on soybean oil and eugenol. European Polymer Journal, 2015. 69: p. 16-28.

56. Chang, S., et al., Synthesis of polylactide- based thermoset resin and its curing kinetics. Polymer International, 2012. 61(10): p. 1492-1502.

57. Vergnaud, J.-M. and J. Bouzon, Cure of thermosetting resins: modelling and experiments. 2012: Springer Science \& Business Media.

58. Auvergne, R., et al., Biobased thermosetting epoxy: present and future. Chemical reviews, 2013. 114(2): p. 1082-1115.

59. Esmaeili, N., et al., Mechanical properties for bio-based thermoset composites made from lactic acid, glycerol and viscose fibers. Cellulose, 2015. 22(1): p. 603-613.

60. Pereira, A.A.C. and J.R.M. d'Almeida, Effect of the hardener to epoxy monomer ratio on the water absorption behavior of the DGEBA/TETA epoxy system. Polímeros, 2016. 26(1): p. 30-37.

61. Murillo, E.A., P.P. Vallejo, and B.L. López, Effect of tall oil fatty acids content on the properties of novel hyperbranched alkyd resins. Journal of Applied Polymer Science, 2011. 120(6): p. 3151-3158.

62. Shao, J. and F. Agblevor, New Rapid Method for the Determination of Total Acid Number (Tan) of Bio-Oils. American Journal of Biomass and Bioenergy, 2015. 4(1): p. 19.

63. Xiong, J.F., et al., Design, synthesis, and characterization of a potential flame retardant poly (lactic acid-co-pyrimidine-2, 4, 5, 6-tetramine) via direct melt polycondensation. Journal of Applied Polymer Science, 2014. 131(10). 
64. Abiko, A., S.-y. Yano, and M. Iguchi, Star-shaped poly (lactic acid) with carboxylic acid terminal groups via poly-condensation. Polymer, 2012. 53(18): p. 3842-3848.

65. Xiao, L., et al., Bio-based green composites with high performance from poly (lactic acid) and surface-modified microcrystalline cellulose. Journal of Materials Chemistry, 2012. 22(31): p. 15732-15739.

66. Nouri, S., C. Dubois, and P.G. Lafleur, Synthesis and characterization of polylactides with different branched architectures. Journal of Polymer Science Part B: Polymer Physics, 2015. 53(7): p. 522-531.

67. Cui, Y., et al., Synthesis of the star-shaped copolymer of E-caprolactone and l-lactide from a cyclotriphosphazene core. Biomacromolecules, 2003. 4(6): p. 1491-1494.

68. Hisham, S.F., et al., Blends of LNR with unsaturated polyester resin from recycled PET: comparison of mechanical properties and morphological analysis with the optimum blend by commercial resin. Sains Malaysiana, 2011. 40(7): p. 729-735.

69. Qiu, L.Y. and Y.H. Bae, Polymer architecture and drug delivery. Pharmaceutical research, 2006. 23(1): p. 1-30.

70. Nawab, Y., et al., Characterization of the cure shrinkage, reaction kinetics, bulk modulus and thermal conductivity of thermoset resin from a single experiment. Journal of Materials Science, 2013. 48(6): p. 2394-2403.

71. Yousefi, A., P. Lafleur, and R. Gauvin, Kinetic studies of thermoset cure reactions: a review. Polymer Composites, 1997. 18(2): p. 157-168.

72. Tiwari, G., et al., Drug delivery systems: An updated review. International journal of pharmaceutical investigation, 2012. 2(1): p. 2.

73. Corneillie, S. and M. Smet, PLA architectures: the role of branching. Polymer Chemistry, 2015. 6(6): p. 850-867.

74. Callister, W.D. and D.G. Rethwisch, Materials science and engineering: an introduction. Vol. 7. 2007: Wiley New York.

75. Kalpakjian, S., S.R. Schmid, and K.V. Sekar, Manufacturing engineering and technology. 2014: Prentice Hall.

76. Storey, R.F., et al., Synthesis of bioabsorbable networks from methacrylate-endcapped polyesters. Polymer, 1993. 34(20): p. 4365-4372.

77. Hodgkinson, J.M., Mechanical testing of advanced fibre composites. 2000: Elsevier. 
1173 78. Mujika, F., On the difference between flexural moduli obtained by three-point and four-

1174

1175

1176

1177

1178

1179

1180

1181

1182

1183

1184

1185

1186

1187

1188

1189

1190

1191

1192

1193

1194

1195

1196

1197

1198

1199

1200

1201

1202

1203

1204

1205

1206

1207

1208

1209

1210

1211

1212

1213

1214

1215

1216

1217

1218

point bending tests. Polymer testing, 2006. 25(2): p. 214-220.

79. Wool, R. and X.S. Sun, Bio-based polymers and composites. 2011: Academic Press.

80. Biwa, S. and B. Storåkers, An analysis of fully plastic Brinell indentation. Journal of the Mechanics and Physics of Solids, 1995. 43(8): p. 1303-1333.

81. Herrmann, K., Hardness testing: principles and applications. 2011: ASM International.

82. Menard, K.P., Dynamic mechanical analysis: a practical introduction. 2008: CRC press.

83. Gabbott, P., Principles and applications of thermal analysis. 2008: John Wiley \& Sons.

84. Chatterjee, A., Thermal degradation analysis of thermoset resins. Journal of applied polymer science, 2009. 114(3): p. 1417-1425.

85. Adekunle, K., D. Åkesson, and M. Skrifvars, Synthesis of reactive soybean oils for use as a biobased thermoset resins in structural natural fiber composites. Journal of applied polymer science, 2010. 115(6): p. 3137-3145.

86. Komkov, M., V. Tarasov, and V. Kuznetsov, The influence of epoxide resin viscosity on impregnation of fiber reinforcement. Polymer Science Series D, 2015. 8(4): p. 292-295.

87. Nouri, S., C. Dubois, and P.G. Lafleur, Effect of chemical and physical branching on rheological behavior of polylactide. Journal of Rheology (1978-present), 2015. 59(4): p. 1045-1063.

88. Cooper- White, J.J. and M.E. Mackay, Rheological properties of poly (lactides). Effect of molecular weight and temperature on the viscoelasticity of poly (l-lactic acid). Journal of Polymer Science Part B: Polymer Physics, 1999. 37(15): p. 1803-1814.

89. Othman, N., et al., Solution and melt viscoelastic properties of controlled microstructure poly (lactide). Journal of Rheology (1978-present), 2011. 55(5): p. 987-1005.

90. Liang, G. and K. Chandrashekhara, Cure kinetics and rheology characterization of soy-based epoxy resin system. Journal of applied polymer science, 2006. 102(4): p. 3168-3180.

91. Li, W.H., A. Wong, and D. Leach. Advances in benzoxazine resins for aerospace applications. in Proc 2010 SAMPE International Symposium, Seattle WA, SAMPE Covina CA. 2010.

92. Du, S., et al., Cure kinetics of epoxy resin used for advanced composites. Polymer international, 2004. 53(9): p. 1343-1347. 
93. Kamal, M. and S. Sourour, Kinetics and thermal characterization of thermoset cure. Polymer Engineering \& Science, 1973. 13(1): p. 59-64.

94. Kamal, M.R., Thermoset characterization for moldability analysis. Polymer Engineering \& Science, 1974. 14(3): p. 231-239.

95. Cole, K., A new approach to modeling the cure kinetics of epoxy/amine thermosetting resins. 1. Mathematical development. Macromolecules, 1991. 24(11): p. 3093-3097.

96. Faruk, O., et al., Biocomposites reinforced with natural fibers: 2000-2010. Progress in Polymer Science, 2012. 37(11): p. 1552-1596.

97. John, M.J. and S. Thomas, Biofibres and biocomposites. Carbohydrate Polymers, 2008. 71(3): p. 343-364.

98. Lubin, G., Handbook of composites. 2013: Springer Science \& Business Media.

99. Mahalle, L., et al., A cradle-to-gate life cycle assessment of wood fibre-reinforced polylactic acid (PLA) and polylactic acid/thermoplastic starch (PLA/TPS) biocomposites. The International Journal of Life Cycle Assessment, 2014. 19(6): p. 1305-1315.

100. Huda, M.S., et al., A Study on Biocomposites from Recycled Newspaper Fiber and Poly(lactic acid). Industrial \& Engineering Chemistry Research, 2005. 44(15): p. 55935601.

101. Lim, L.T., R. Auras, and M. Rubino, Processing technologies for poly(lactic acid). Progress in Polymer Science, 2008. 33(8): p. 820-852.

102. Olabisi, O. and K. Adewale, Handbook of thermoplastics. Vol. 41. 2016: CRC press.

103. Pascault, J.-P., et al., Thermosetting polymers. Vol. 64. 2002: CRC Press.

104. Rowell, R.M., Challenges in Biomass-Thermoplastic Composites. Journal of Polymers and the Environment, 2007. 15(4): p. 229-235.

105. Oksman, K., M. Skrifvars, and J.-F. Selin, Natural fibres as reinforcement in polylactic acid (PLA) composites. Composites science and technology, 2003. 63(9): p. 1317-1324.

106. Wambua, P., J. Ivens, and I. Verpoest, Natural fibres: can they replace glass in fibre reinforced plastics? composites science and technology, 2003. 63(9): p. 1259-1264.

107. Qin, L., et al., Mechanical and thermal properties of poly (lactic acid) composites with rice straw fiber modified by poly (butyl acrylate). Chemical Engineering Journal, 2011. 166(2): p. 772-778. 
108. Raquez, J.-M., et al., Thermosetting (bio) materials derived from renewable resources: $a$ critical review. Progress in Polymer Science, 2010. 35(4): p. 487-509.

109. Bummer, P.M., Physical chemical considerations of lipid-based oral drug deliverysolid lipid nanoparticles. Critical Reviews ${ }^{\mathrm{TM}}$ in Therapeutic Drug Carrier Systems, 2004. 21(1).

110. Shin, H., S. Jo, and A.G. Mikos, Biomimetic materials for tissue engineering. Biomaterials, 2003. 24(24): p. 4353-4364.

111. Tabata, Y., The importance of drug delivery systems in tissue engineering. Pharmaceutical science \& technology today, 2000. 3(3): p. 80-89.

112. Saltzman, W.M. and W.L. Olbricht, Building drug delivery into tissue engineering design. Nature Reviews Drug Discovery, 2002. 1(3): p. 177-186.

113. Whang, K., T.K. Goldstick, and K.E. Healy, A biodegradable polymer scaffold for delivery of osteotropic factors. Biomaterials, 2000. 21(24): p. 2545-2551.

114. Sheridan, M., et al., Bioabsorbable polymer scaffolds for tissue engineering capable of sustained growth factor delivery. Journal of Controlled Release, 2000. 64(1): p. 91-102.

115. Langer, R., Biodegradable polymer scaffolds for tissue engineering. Nat. Biotechnol, 1994.

116. Saltzman, W.M. and T.R. Kyriakides, Chapter 20 - Cell Interactions with Polymers A2 Lanza, Robert, in Principles of Tissue Engineering (Fourth Edition), R. Langer and J. Vacanti, Editors. 2014, Academic Press: Boston. p. 385-406.

117. Lucke, A., et al., Biodegradable poly (D, L-lactic acid)-poly (ethylene glycol)monomethyl ether diblock copolymers: structures and surface properties relevant to their use as biomaterials. Biomaterials, 2000. 21(23): p. 2361-2370.

118. McCabe-Sellers, B.J. and S.E. Beattie, Food safety: emerging trends in foodborne illness surveillance and prevention. Journal of the American Dietetic Association, 2004. 104(11): p. 1708-1717.

119. Byun, Y., Y.T. Kim, and S. Whiteside, Characterization of an antioxidant polylactic acid (PLA) film prepared with $\alpha$-tocopherol, BHT and polyethylene glycol using film cast extruder. Journal of Food Engineering, 2010. 100(2): p. 239-244.

120. Dainelli, D., et al., Active and intelligent food packaging: legal aspects and safety concerns. Trends in Food Science \& Technology, 2008. 19: p. S103-S112.

121. Yam, K.L., P.T. Takhistov, and J. Miltz, Intelligent packaging: concepts and applications. Journal of Food Science, 2005. 70(1): p. R1-R10. 
122. Wessling, C., T. Nielsen, and J.R. Giacin, Antioxidant ability of BHT- and $\alpha$-tocopherol-impregnated LDPE film in packaging of oatmeal. Journal of the Science of Food and Agriculture, 2001. 81(2): p. 194-201.

123. Wessling, C., et al., Retention of $\alpha$-tocopherol in low-density polyethylene (LDPE) and polypropylene $(P P)$ in contact with foodstuffs and food-simulating liquids. Journal of the Science of Food and Agriculture, 1999. 79(12): p. 1635-1641.

124. Jamshidian, M., E.A. Tehrany, and S. Desobry, Release of synthetic phenolic antioxidants from extruded poly lactic acid (PLA) film. Food Control, 2012. 28(2): p. 445-455.

125. Soto-Cantú, C., et al., Release of butylated hydroxytoluene from an active film packaging to asadero cheese and its effect on oxidation and odor stability. Journal of dairy science, 2008. 91(1): p. 11-19.

126. Morgan, A.B. and J.W. Gilman, An overview of flame retardancy of polymeric materials: application, technology, and future directions. Fire and Materials, 2013. 37(4): p. 259279.

127. Bourbigot, S. and G. Fontaine, Flame retardancy of polylactide: an overview. Polymer Chemistry, 2010. 1(9): p. 1413-1422.

128. Gledhill, R., et al., Relationship between mechanical properties of and crack progogation in epoxy resin adhesives. Polymer, 1978. 19(5): p. 574-582. 

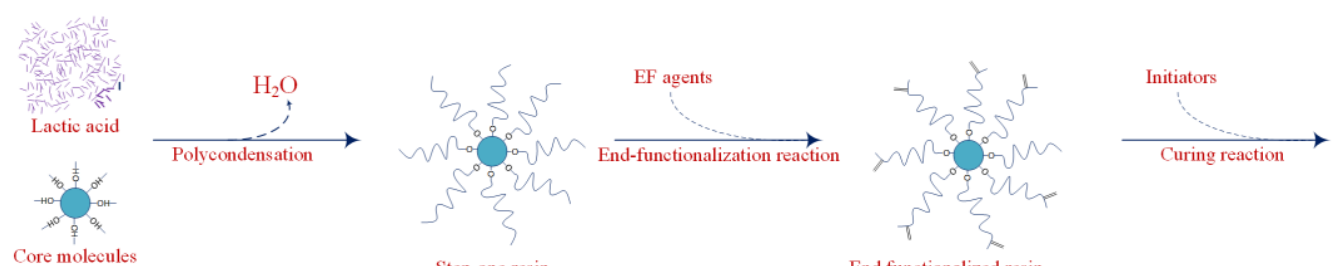

Step-one resin

End functionalized resin

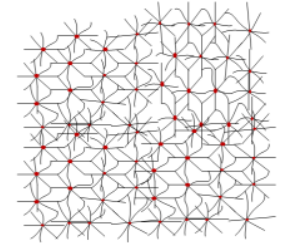

Thermoset network

1338 